\title{
Oral Protein Therapy for the Future - Transport of Glycolipid-Modified Proteins: Vision or Fiction?
}

\author{
Günter Müller
}

Genetics, Department of Biology I, Ludwig Maximilians University Munich Biocenter, Munich, Germany

\section{Key Words}

Protein therapeutics $\cdot$ Oral delivery $\cdot$ Personalized medicine $\cdot$ Post-translational modification $\cdot$ Protein trafficking

\begin{abstract}
The reliable and early diagnosis of common complex multifactorial diseases depends on the individual determination of all (or as many as possible) polymorphisms of each susceptibility gene together with amount and type of the corresponding gene products and their downstream effects, including the synthesis and flux of metabolites and regulation of signalling processes. In addition, this system's biologydriven personalized diagnosis must be accompanied by options for personalized reliable and early therapy. In the midterm, the direct substitution or inhibition of the proteins encoded by the corresponding defective gene products of the susceptibility genes exerting lower or higher activity by administration of the 'normal' proteins or inhibitory antibodies, respectively, seems to be most promising. The critical hurdle of oral bioavailability as well as transport into the cytoplasm of the target cells, if required, could be overcome by therapeutic proteins with carboxy-terminal modification by glycosylphosphatidylinositol (GPI). This may be deduced from recent experiments with rat adipocytes. Here this mem-
\end{abstract}

brane-anchoring glycolipid structure induces the sequential transport of proteins from special regions of the plasma membrane via the surface of intracellular lipid droplets to special membrane vesicles, which are finally released from the adipocytes together with the associated GPI proteins. It remains to be studied whether similar molecular mechanisms operate in intestinal epithelial cells and may enable the transport of GPI proteins from the intestinal lumen into the blood stream. If so, modification of proteins encoded by (combinations of) susceptibility genes with GPI could significantly facilitate the personalized therapy of common diseases on the basis of 'inborn' safety, efficacy, rapid realization and oral application.

Copyright $\odot 2010$ S. Karger AG, Basel

\section{Introduction - Personalized Therapy}

During the past decade, knowledge about the involvement of a multitude of susceptibility genes and novel complete mechanisms in the pathogenesis of complex and common multifactorial diseases, such as type II diabetes, has been accumulating [1-4]. Nevertheless, currently these novel findings have not been translated into corresponding methods and technologies for their prognosis and diagnosis [5]. This may be due to the relatively

\section{KARGER}

Fax +4161306 1234

E-Mail karger@karger.ch

www.karger.com
(C) 2010 S. Karger AG, Basel

0031-7012/10/0862-0092\$26.00/0

Accessible online at:

www.karger.com/pha
Günter Müller

Sanofi-Aventis Deutschland GmbH, R\&D, Diabetes

Industrial Park Hoechst, Bldg. 821, DE-65926 Frankfurt am Main (Germany)

Tel. +4969305 4271, Fax +496930581901

E-Mail Guenter.Mueller@sanofi-aventis.com 
moderate predictive power derived from the determination of the individual complete genetic profile (genomics) which, in part, is caused by inadequate numbers of (combinations of) (single nucleotide) polymorphisms identified in susceptibility genes so far $[6,7]$. For principal reasons this obstacle cannot be overcome by a mere increase in sample size $[8,9]$. However, it may be weakened by the inclusion of additional 'downstream parameters' encompassing the complete patterns of proteins (proteomics), lipids (lipidomics), metabolites (metabolomics) and their fluxes (fluxomics) of the patient versus control subject [5, 10-12]. Unfortunately, the present technologies for genomics, proteomics, lipidomics and metabolomics are relatively cost-intensive. Nevertheless, this burden would be accepted facing the enormous social and economical consequences for the community and the health problems for the affected individual patient, which are associated in the long term with common complex diseases, in general, and type II diabetes, in particular. However, the acceptance by the society for the need of a timely and reliable diagnosis is based on the availability of adequate options for prevention and therapy, which may include, but must not be limited to, advices for a (more) healthy life style, such as food restriction and intensified physical exercise (albeit there is no doubt about their benefit for the prevention of the majority of common diseases in the Western countries). Clearly the expenditure for personalized diagnosis, which has to be supported by all (affected as well as non-affected) members of our health care systems, cannot be justified by the currently implemented strategies of non-personalized prevention and therapy. They simply divide the population into normal ('control') and affected ('case'), and recommend first-, second- and third-line (or more) treatments. For example, the therapy of type II diabetes is currently based on 6 approved drug classes encompassing both small molecules (metformin, sulfonylureas, glitazones, DPP-IV inhibitors) and (unmodified or modified) proteins (insulin and analogues, glucagon-like polypeptide-I and analogues). Certainly, this repertoire does not meet the requirements for the individualized treatment of this common disease with its estimated 2,000-3,000 susceptibility genes and even higher numbers of the underlying polymorphisms and combinations thereof. The resulting heterogeneity is further amplified by individual polymorphisms in protective genes and positive or negative environmental influences [5]. Thus, the currently available therapies for common complex diseases do not fit to the multitude and heterogeneity of the underlying disease mechanisms.

Transport of Glycolipid-Modified Proteins: Vision or Fiction?

\section{Traditional Options for Therapy}

Which options for personalized therapy are currently in our hands, at least in principle (fig. 1)? (1) The abnormal function or synthesis of a polymorphic/mutant gene product encoded by the susceptibility gene may be corrected (that is, inhibited/activated or down-/upregulated) by orally available small drug molecules. (2) The polymorphic/mutant variant of the susceptibility gene may be replaced by the corresponding wild-type genes (gene therapy). (3) The abnormal tissues/cells suffering from the expression of the polymorphic/mutant variant of the susceptibility gene may be replaced by normal tissues/ cells grown in culture (regenerative medicine and tissue engineering). (4) The missing or overactive function or synthesis of a polymorphic/mutant gene product encoded by the susceptibility gene may be compensated for by delivery of the wild-type gene product or neutralizing antibodies against the corresponding polymorphic/mutant gene product (protein therapeutics and therapeutic antibodies (fig. 1). Each of these strategies will lead to personalized therapy for a given complex common disease, that is, tailored to the individual genetic profile and individual complete pathogenic mechanism. In case of type II diabetes, these strategies may target components of the glucose-sensing system in pancreatic $\beta$ cells and intestinal L cells, insulin production and secretion in the $\beta$ cells, or insulin action in muscle, adipose and/or liver cells or combinations thereof.

By nature, there are advantages and disadvantages associated with each of these therapeutic strategies, which are only outlined here in brief (fig. 1). Gene therapy and regenerative medicine are believed to harbour the greatest potential and application field for the future, but unfortunately have recently experienced serious doubts and issues concerning safety, production and realization. The success of gene therapy is highly dependent on the quality of the delivery vector, which can be generally categorized into viral and non-viral origin [13]. Viral vectors are highly efficient. They are currently still the most powerful tools for gene transfection. However, some viral vectors show limited loading capacity, are difficult to produce in large scale and, most importantly, pose severe safety risks due to their oncogenic potential and their inflammatory and immunogenic effects, which prevent them from repeated administration. To overcome these limitations, non-viral vectors have emerged as a promising alternative for gene delivery. A number of non-viral siRNA delivery approaches have now been reported in vivo, including in non-human primates and humans [13- 


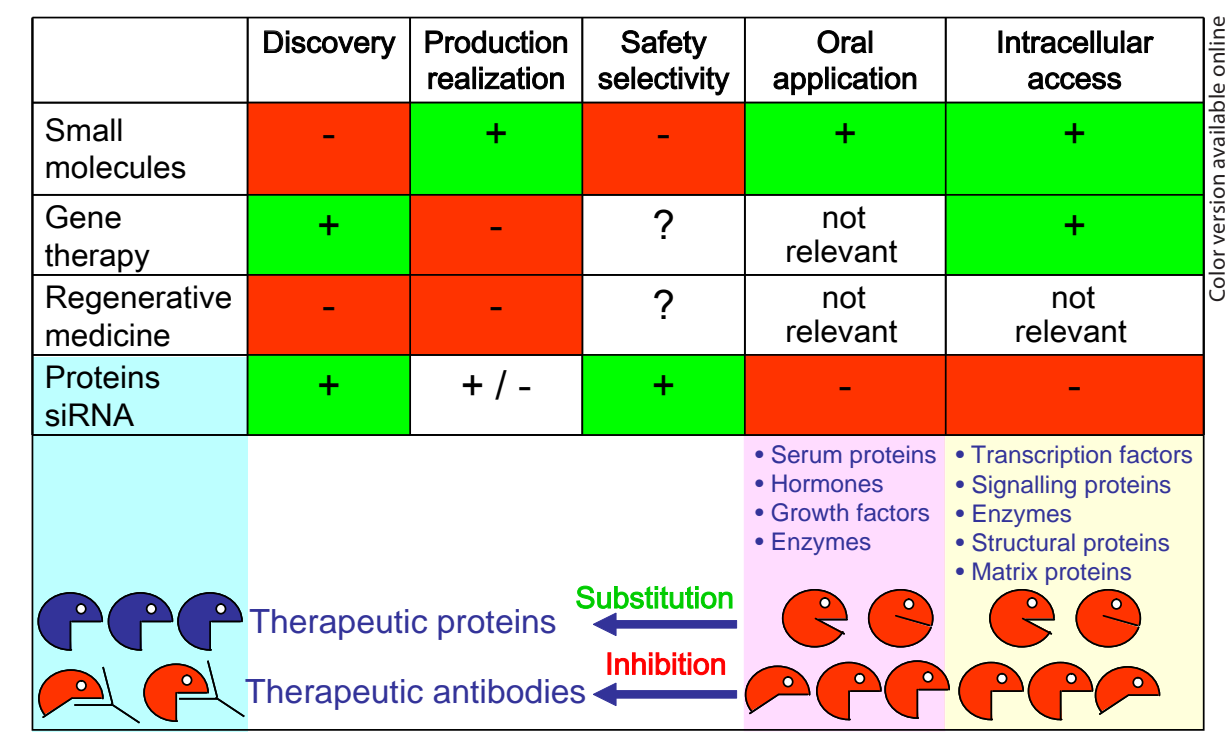

Fig. 1. Current options for personalized prevention and therapy. Principal advantages and disadvantages of small drug molecules (chemicals), gene therapy (viral and non-viral vectors, non-vector-based vehicles), regenerative medicine (embryonic and adult stem cells, tissue engineering) and gene products (proteins and siRNA/microRNA encoded by susceptibility and disease genes) are given. Wild-type or appropriately modified versions of the latter can be used as therapeutic proteins which substitute for the missing or hypoactive gene products or for the generation of therapeutic antibodies which inhibit the over-expressed or hyperactive gene products.
17], among them hydrodynamic injection, cholesterol conjugation, cationic delivery systems such as liposomes and lipoplexes, as well as polymer- and peptide-based delivery systems, and other delivery routes, such as intraocular delivery, intratumoral delivery, local in vivo electroporation to muscle, local delivery to the central nervous system and intranasal delivery to the airway $[18,19]$.

Small chemicals (synthesized and natural molecules), in general, are easily produced in small and large scale by modern synthesis methods and can often be delivered as a pill via the oral route into the circulation and gain access to the abnormal tissue (by diffusion) as well as to the cytoplasm of the target cell (fig. 1). However, the past two decades of enormous biotechnological expenditure worldwide with state-of-the-art high-throughput screening, structural biology, bioinformatics and rational drug design finally resulted in a rather disappointing outcome of approved small molecule drugs. This clearly demonstrates the considerable difficulties inherent in the discrimination of 'chemicals' and 'drug-like' molecules, that is, the selection from libraries containing millions of chemical substances those compounds with potential for subsequent successful step-by-step optimization via lead structures to drug candidates in course of several rounds of structural variation/modification with the help of ra- tional design and structural biology. The reasons for these difficulties are complex and multi-facetted and not only based on scientific reasons. However, in any case, small chemicals intrinsically suffer from limited selectivity between the desired cellular target and unwanted offtargets, which represent large macromolecules, such as proteins and nucleic acids. This selectivity issue is intimately associated with safety problems and considerably impairs multi-parameter optimization. Therefore, it is not too surprising that during the past decade the identification of susceptibility genes for common diseases has over-run the introduction of novel small molecule drugs for their therapy, which target the corresponding gene products. This apparently huge problem with the identification of small drug molecules is in contrast to the need to obtain drugs for each defective/missing or hyperactive/ overproduced gene product encoded by the multiple susceptibility genes and underlying the common diseases.

The gene products encoded by susceptibility genes are intrinsically characterized by exquisite potency and, in consequence, safety, in general, as well as by efficient quasi 'inborn' discovery (fig. 1). Their wild-type versions represent 'natural' cell components. Therefore, upon their identification they may be used for therapy directly by substitution of defective or missing gene products or in- 


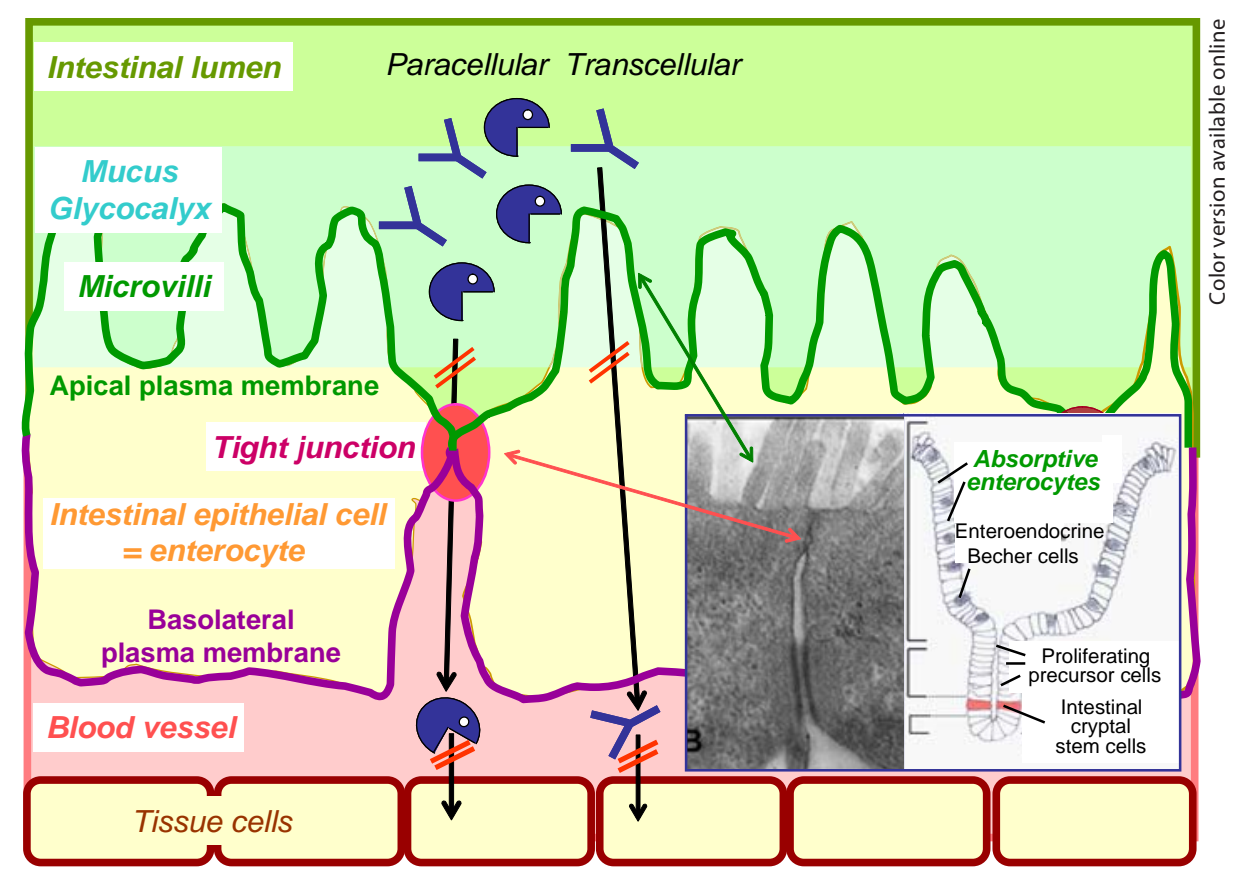

Fig. 2. The intestinal permeability barrier. After ingestion and arrival in the intestinal lumen the therapeutic protein or antibody has to pass the glycocalyx and mucus layers and then be transported into blood vessels and underlying tissue cells. Typically, proteins do not follow the transcellular route across the microvilli of the apical plasma membrane or the paracellular route across the protein complexes of tight junctions (oval). These connect the neighbouring enterocytes to the intact and sealed intestinal epithelial cell layer preventing macromolecules contained in the food from access to the circulation. The inset shows that distinct populations of enterocytes are arranged in the so-called brush border structures which line the intestinal wall with absorptive enterocytes located at the tip, stem cells located at the bottom in so-called crypts, proliferative precursor cells derived from the stem cells and enteroendocrine 'Becher' cells located between the tips and the crypts and engaged in the (glucose-dependent) synthesis and release of neuroendocrine proteins, such as GLP-1, for the control of food intake and insulin release. directly by blockade of over-active or over-produced gene products using neutralizing antibodies directed against them. However, therapeutic proteins and antibodies have to overcome a number of critical hurdles prior to beneficial systemic action. One of the most important is the passage along the gastrointestinal tract and the transport across intestinal epithelial cells into the circulation (fig. 2). For susceptibility gene products with major site of action in the serum (such as plasma enzymes) or interstitial spaces (such as polypeptide hormones) this so-called oral bioavailability may represent the only barrier for targeting their primary mode of action. Gene products with primary mode of action in the cytoplasm (such as transcription factors, signalling proteins) have to be transported from the circulation via the extracellular matrix across the plasma membrane of the target tissue/cells, in addition (fig. 2). This is typically not managed by therapeutic proteins and antibodies and therefore they have to be injected according to their site of action (that is, sub- cutaneously, intravenously, intramuscularly or intraperitoneally).

Consequently, personalized prevention and therapy based on the injection of gene products into the circulation is per se prevented by their inability to be transported into the target cells or considerably limited by the known patient's compliance toward their non-oral administration. In particular, the latter holds true for common diseases, such as type II diabetes, which are often characterized during the initial stages by only low to moderate consequences for the individual life style and quality. However, many common diseases underlie vicious cycles of their pathogenesis finally leading to irreversible damages, which resist improvement by late onset of non-oral administration of therapeutic proteins and antibodies. In former times, the emphasis of oral delivery of therapeutic proteins and antibodies was more on convenience and avoidance of needles. With the current understanding of the pathogenesis of multifactorial com- 
plex diseases, such as type II diabetes, additional emphasis has also been placed on the physiological importance of the most appropriate, that is natural, route of delivery of the protein therapeutic to its site(s) of action in the target tissues and cells. In case of therapy of type II diabetes this is the hepatic route [20]. Existing insulin therapies including newer, injectable and short-acting analogues introduce insulin at the periphery and do not mimic the normal, physiological portal-to-peripheral gradient. These therapies continue to over-insulinize the periphery resulting in undesirable side effects, such as peripheral hyperinsulinemia with resulting insulin resistance, weight gain and hypoglycaemia. With hepatically delivered oral insulin there is the possibility of achieving high portal vein concentrations of insulin without sustained peripheral hyperinsulinemia. The physiological rational and therapeutic advantage for oral insulin has meanwhile been widely acknowledged by diabetologists [20]. Taken together, the pathogenic mechanisms for common complex diseases, which are based on multiple susceptibility genes, may be interrupted by substitution of the relevant gene products or introduction of the relevant neutralizing antibodies in the circulation and, if required, in the target cells in course of their oral delivery and, if required, subsequent transport across the plasma membrane (fig. $1,2)$.

\section{Transport across Intestinal Epithelial Cells}

The greatest barriers to the oral delivery of therapeutic protein and antibodies lie in the gastrointestinal tract. Dietary proteins do not normally cross the gastrointestinal epithelium intact, but must first be broken down to their constituent free amino acids and peptides by various enzymes located throughout the gastrointestinal tract. These constituents are then absorbed by the gastrointestinal epithelium. Of course, this route of protein absorption destroys almost all physiological activity of the original protein or polypeptide and explains why typical oral bioavailabilities of proteins are usually less than 1-2\% [21]. Therefore, despite the fact that recombinant DNA technology has allowed for ever increasing numbers of therapeutic proteins and antibodies, delivery of these drugs is still generally through injection. For the past 8 decades, a great deal of work has focused on attempts to develop non-invasive methods of delivering protein drugs with the oral route clearly being the most convenient and desired one.
The earliest attempts for oral delivery of a protein therapeutic date back to the 1930s and were devoted to shortacting insulin formulations. These studies were performed to understand if insulin could be adsorbed via the portal vein by directly injecting insulin into the intestinal loop [22]. In fact, 30 years later it was demonstrated that there may be some, albeit very limited, ability for proteins to cross the intestinal epithelium intact if administered directly in the intestinal lumen thus avoiding the acidic environment of the stomach [23]. In another study, a hexylresorcinol solution containing insulin was administered to 10 healthy volunteers. The study successfully showed a reduction in blood glucose levels, but concluded that oral delivery of insulin exhibits great interindividual variability and poor bioavailability [24]. According to these early studies [22-24], some proteins and peptides, most often lipophilic ones, have actually been shown to have useful oral bioavailabilities. Insulin, unfortunately, does not and is effectively stopped by the natural barriers to protein delivery. Overcoming these barriers is the focus of efforts to develop oral delivery systems for therapeutic proteins and antibodies, in general, and insulin, in particular.

Which are the main reasons for the failure of proteins to become transported after their oral ingestion from the intestinal lumen into the blood vessels, the interstitial spaces surrounding the target tissues and the cytoplasm of the target cells? The epithelial layer lining the gastrointestinal tract is a tightly bound collection of cells with minimal leakage and forms a physical barrier to absorption (fig. 2). It is made up of a single layer of columnar epithelial cells supported by the lamina propria and muscularis mucosa. The epithelium folds to form villi (the brush border) and each epithelial cell also possesses microvilli, uniform one-micrometer finger-like projections, on its apical surface. Together, these structures increase the absorptive area of the intestinal tract by approximately two orders of magnitude [25]. However, these structures hinder the absorption of proteins as the microvilli also contain digestive enzymes. In addition to these formidable barriers, on top of the epithelial layer lies the glycocalyx, a layer of sulphated mucopolysaccharides, and a layer of mucus consisting of glycoproteins, enzymes, electrolytes and water. Glycocalyx and mucus present yet another physical barrier to the transport of proteins.

Neighbouring epithelial and endothelial cells are tightly bound to one another by specific protein complexes, the so-called tight junctions of zona occludens, which ensure their assembly into stably sealed tissues. Proteins in the circulation or in the interstitial space are usually 
prevented from 'transcellular' passage across the apical plasma membrane via the cytoplasm to and across the basolateral plasma membrane as well as from 'paracellular' passage between the basolateral plasma membranes of neighbouring epithelial and endothelial cell layers via the tight junctions (fig. 2). The size and hydrophilic nature of typical serum proteins (and thus putative protein therapeutics), such as enzymes, hormones, growth factors or antibodies, are not compatible with their passive or facilitated diffusion across plasma membranes or tight junctions. Furthermore, apparently there was no evolutionary pressure for the development of specific active and receptor-mediated mechanisms for the transport of proteins from the intestinal lumen into the circulation, whereas those have evolved for the transport of hormones and growth factors from the circulation into the target tissues.

In addition to the physical barrier provided by the intestinal epithelium, proteins face another, possibly greater, barrier in the form of digestive enzymes acting along the gastrointestinal tract. Protein digestion by proteases starts in the stomach and is continued by many different enzymes located throughout the intestinal tract [26]. Pepsins are located in the stomach and trypsin, chymotrypsin and carboxypeptidases released from the pancreas are located in the small intestinal lumen [27]. These pancreatic enzymes are responsible for only about $20 \%$ of enzymatic degradation of ingested proteins. The remainder of the degradation occurs at the brush-border membrane or in the cytosol of enterocytes of the intestinal tract by various peptidases, among them the so-called insulin-degrading enzyme [28]. Many attempts have been made to overcome these enzymatic barriers (see below). But this is certainly a difficult challenge since the presence of just one or two of these enzymes could lead to total denaturation or destruction of a protein drug.

The final major barrier to the development of effective oral protein delivery systems rests in the actual fabrication methods for the formulation to be used. Unlike low molecular weight drugs, proteins have a complex internal structure which helps define their biological activity. Any alteration in the primary (amino acid sequence), secondary (two-dimensional structure), tertiary (folding) or quaternary structure (combination of polypeptide subunits) can result in the deactivation of a protein. These alterations may be caused by even the slightest changes in the environment (or even microenvironment) of the protein. The most likely variables which can affect protein structure and stability are related to the temperature, $\mathrm{pH}$, solvent, ingredients and crystallinity states of the protein.
These considerations are most pertinent when using polymer-encapsulated formulations. Many of the basic encapsulation methods used in the production of polymer-based protein drug delivery systems can easily disrupt the delicate protein structure rendering the protein inactive. Therefore, although the characterization of the releasing kinetics of therapeutic proteins and antibodies from putative drug delivery systems is important, understanding the stability of the protein is just as critical. This topic should not be neglected when discussing barriers to oral protein delivery $[25,29]$. Despite these apparent challenges, there have been intensive efforts of pharmacologist and biotechnologists during the past decades to enable or improve the oral bioavailability of therapeutic proteins and antibodies for the chronic therapy of common diseases, such as cancer, cardiovascular diseases and metabolic diseases, including type II diabetes, on the basis of a variety of distinct and sophisticated technologies, which are mentioned here only in brief (fig. 3).

\section{General Approaches for the Oral Delivery of Protein Therapeutics}

Bypassing of the intestinal epithelial transport barrier has been tackled by several approaches [30, 31]. (1) The most common strategy which has been followed is encapsulation of the protein drug in liposomes and micro- or nanoparticles. Nanoparticle formulations using mucoadhesive polymers, such as chitosan, poly(lactic-)co-glycolic acid, poly- $\gamma$-glutamic acid and alginate, poly(alkyl-) cyanoacrylate microparticles and $\beta$-cyclodextrin liposomes have been studied extensively [32-37]. The protein drugs encapsulated in these polymers are apparently physically protected from enzymatic degradation and it has been shown clearly that such particles cross the epithelial layer through Peyer's patches [38]. While some of the encapsulated protein drugs have been demonstrated to exert the desired physiological effect in appropriate animal models, such as lowering of blood glucose in streptozotocin-diabetic rats in the case of insulin, further development has not been reported. Presumably, the nanomaterials, which are currently in use, 'actively' induce the transient opening of the tight junctions in course of their direct binding to protein components of the zona occludens and thereby enable the paracellular passage of the encapsulated therapeutic proteins into the circulation. One critical disadvantage of this 'site-specific' delivery and 'colonic absorption' could be the inability to adequately correct and compensate for all physiological as- 


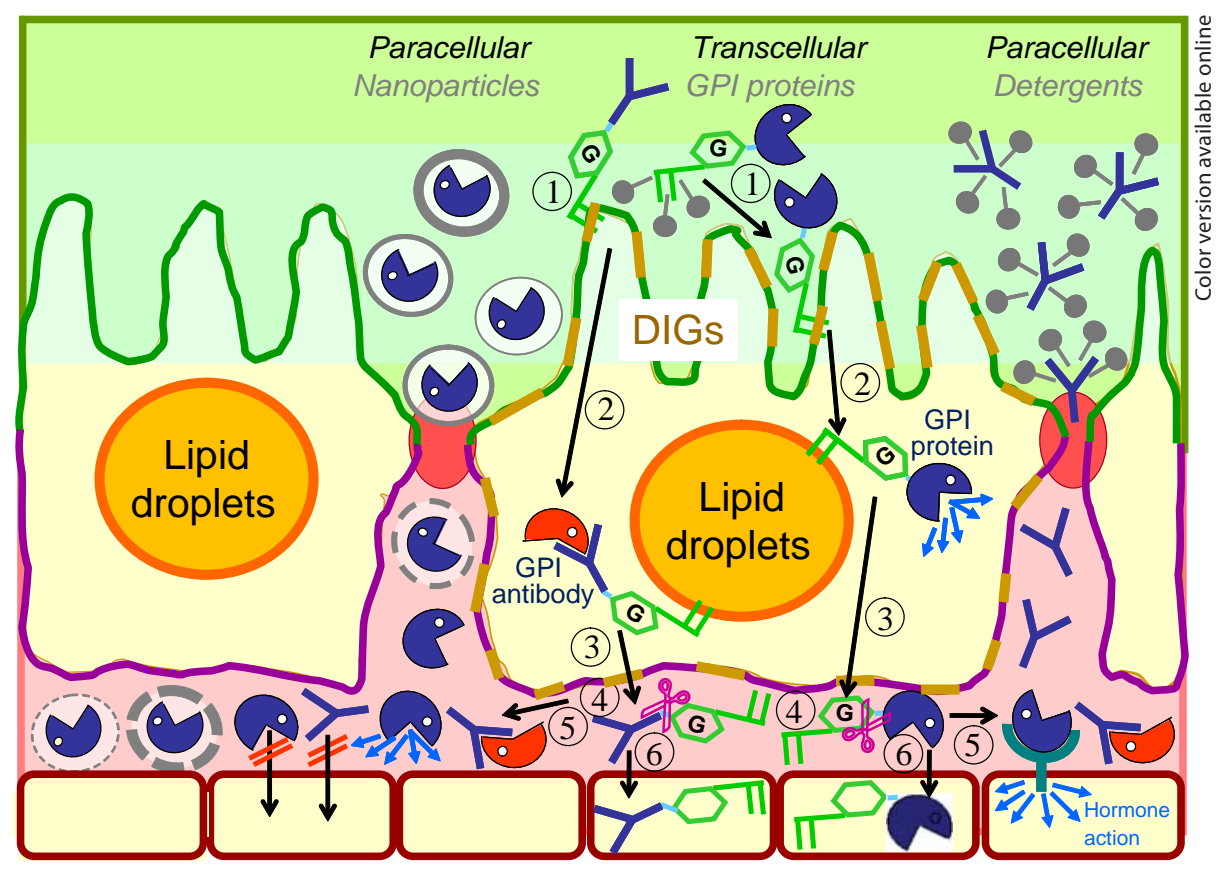

Fig. 3. Current and hypothetical options for the passage of therapeutic proteins and antibodies across the intestinal permeability barrier into the circulation and the putative further targeting to underlying tissues, such as pancreatic $\beta$, muscle and adipose cells, for physiological (for example hormone) action via paracellular or transcellular routes, which are used by permeability enhancers/detergents and nanoparticles (grey continuous or interrupted envelope) or GPI proteins, respectively. The critical roles of DIGs (brown lines, colour only in online version), lipid droplets and the GPI-specific phospholipase D (scissors) in the individual steps 1-6 of intra- and intercellular trafficking of the GPI proteins (in blue) and GPI antibodies (in red), as well as of nanoparticles, penetration enhancers/detergents and tight junctions (red ovals) in paracellular transport are explained in the text. pects of the missing or defective endogenous gene product, such as the loss of first-phase insulin secretion in the case of insulin.

(2) The prevention of the enzymatic degradation in the gastrointestinal tract in course of delivery of the protein drug along with a protease inhibitor could represent a useful strategy, too. In one pilot study, 5 different protease inhibitors were tested individually along with insulin [39]. It was found that bacitracin, sodium glycocholate and camostat mesilate promoted the absorption of insulin, while soya bean trypsin inhibitor has very little effect on the absorption. The study concluded that co-administration of protease inhibitors is one possible approach to improve the absorption of protein drugs, such as insulin, from the gastrointestinal tract [39], presumably due to prolonged survival period of the intact protein drug at the intestinal epithelium which raises the probability of its absorption. A general limitation of this approach is that the long-term effect of chronic administration of protease inhibitors is unknown and may result in protein malabsorption and other adverse side effects. This may be one reason why this approach has not reached clinical trials so far for the most attractive candidates for oral protein delivery in the long term, such as insulin. Alternatively, derivatization of polypeptide drugs by using polyethylene glycol [40] and their encapsulation in $\mathrm{pH}$ responsive gels and films [41] or in enteric-coated capsules containing sodium salicylate [42], which become gradually dissolved or leaky along passage in the gastrointestinal tract, have been reported to prevent their enzymatic degradation and to enhance their absorption [43]. A number of these promising approaches have been taken into the clinics.

(3) Several permeation enhancers have been analysed for their capability to increase the efficacy of oral protein delivery. The most commonly tried permeation enhancers are bile salts or fatty acids for increasing the permeability across the intestinal cell walls, presumably via the transcellular route. Salts of fatty acids like caprate, caprylate, laurate or palmitate have been tested for oral delivery of insulin, other peptides and certain macromolecules with variable success $[44,45]$. The co-administration of 
other penetration enhancers based on detergent-like molecules and micelles, such as pluronic acid [46], seems to destabilize or weaken the tight junctions facilitating the paracellular routing of protein drugs [47]. Moreover, a specific toxin, zonula occludens toxin, is currently being assessed as permeation enhancer for insulin and has been demonstrated to be effective in reducing blood glucose levels in animal models of diabetes [48]. In fact, this toxin apparently opens up the tight junctions in effective and reversible fashion and thereby manages to improve the permeability of protein drugs, such as insulin. However, these permeation enhancers could potentially damage or even dissolve the gastrointestinal barrier and thereby facilitate the access of undesired small and large compounds from the intestinal lumen into the circulation with increased risks for local inflammations and gastrointestinal infections. Furthermore, prior to routine therapeutic application, the unspecific oral delivery of proteins and protein fragments originating from the food as an unwanted consequence of the general loss of the permeability barrier and protective function formed by the enterocytes has to be excluded for each type and each combination of penetration enhancers. Thus, long-term toxicity of this approach needs to be evaluated on a caseby-case basis. Considering the intrinsic specificity issue of this 'general permeation enhancer' approach and the challenging task to prove its safety in the long term, the encapsulation of the therapeutic proteins and antibodies into nanoparticles seems to be more promising (fig. 3) $[49,50]$. Taken together, multiple approaches for oral protein delivery have been tested so far and offered early promise, but very few of them have made it beyond preclinical stages.

\section{From the Circulation to Target Tissues and into Target Cells}

Irrespective of the strategy used to overcome the barrier of the gastrointestinal tract (see above), after successful para- or transcellular passage of the therapeutic proteins and antibodies across the intestinal epithelial cells, they only manage to act extracellularly in the circulation (for example by inhibition of serum enzymes, such as endothelial lipase) in case of neutralizing antibodies or in the interstitial tissue spaces or at the surface of the target cells (for example by activation of cell surface receptors, such as the insulin receptor) in case of hormones and growth factors (fig. 3). The penetration of the 'nude' therapeutic protein or antibody into the target cell to gain ac- cess to the cytoplasm and relevant organelles, for example the nucleus, is typically extremely inefficient due to the permeability barrier formed by the plasma membranes for large hydrophilic macromolecules. This represents a general and serious limitation for the use of protein therapeutics. Thus, the development of safe and effective drug carriers that can be orally administered but will selectively deliver therapeutic protein drugs into the diseased cells without harming normal cells is an additional and essential goal of nanomedicine [51,52].

Interestingly, the size of the nanoparticles and the thickness and type of the nanomaterials used apparently determines the systemic trafficking of the nanocarriers in the circulation following their transit across the intestinal barrier (fig. 3; thick or thin continuous or interrupted envelopes). This could open the possibility for specific targeting of therapeutic proteins and antibodies to the affected tissues, such as muscle, fat, liver and pancreas for type II diabetes therapy or to proliferating malignant cells for cancer therapy. The strategy of 'passive targeting' relies on the relatively selective extravasation and retention of long-circulating nanocarriers on the basis of specific structural features of the diseased tissue. The strategy of 'active targeting' is based on the modification of the surface of nanosized carriers with ligands that can specifically recognize the diseased cells. These two clinically relevant and nanocarrier-based targeting strategies rely on the specific interaction between the ligands (antibodies, peptide mimics or nucleic acids) on the carrier surface and the corresponding receptors expressed on the diseased cells. For example, human epidermal growth factor receptor-2 [53-55], folic acid receptor [46] and vasoactive intestinal peptide receptors [56] have been investigated as biomarkers for nanocarriers targeted to breast tumours. Recently, new targeting strategies have emerged as a way of improving the targeting efficiency of the nanocarriers. They are based on the unique microenvironment of surrounding tumour cells ('tumoral extracellular environment') as a molecular cue to activate longcirculating nanocarriers to release the drug or facilitate their cellular uptake upon arrival at the target tumour sites.

Many different macromolecular structures, such as drug-polymer conjugates, micelles, liposomes, dendrimers and nanoparticles, have been designed to transport drugs to their intended target tissues and cells. Micelles can be made from amphiphilic block co-polymers that self-assembly into small spherical structures $[47,57]$. Liposomes are vesicles made of phospholipid bilayers that can encapsulate drugs in their luminal cores or interfaces 
between the bilayers [57]. Nanoparticles are generally polymeric matrices in the form of nanosized colloids that can encapsulate a drug through physical entrapment (association between the drug and polymer) or chemical conjugation (creating a chemical bond between the drug and polymer) $[49,50]$.

Some of the recently reported targeting strategies have good potential to achieve both passive and active targeting effects. These strategies aim to create nanocarriers that maintain the stealth property during circulation (passive targeting) and then transform to more cell-interactive form (active targeting) upon arrival at the target sites on the basis of the unique extracellular environment of the diseased cells. For instance, tumours develop unique microenvironments, such as slightly acidic $\mathrm{pH}$ [58] and a high level of proteinases [59]. The extracellular $\mathrm{pH}$ of malignant tissues is generally more acidic $(\mathrm{pH} 6.5-$ 7.2) due to the increased glycolysis of tumour cells, which makes them produce more lactic acid and release it into the surrounding milieu than normal cells $[60,61]$. The overproduction of enzymes, such as the matrix metalloproteinases, is also common for most proliferating malignant cells, since they are essential for angiogenesis, metastasis, and other extracellular signalling events involved in tumour propagation [59]. Overexpression of metalloproteinases has been explored as a way of targeting and 'turning on' of imaging agents for the allocation of tumours or other lesions [62-64].

However, for chronic therapeutic application of nanoparticles, the possibility and extent of their systemic entry has to be investigated, including the relevant degrading and eliminating pathways. In case of oral delivery of therapeutic proteins and antibodies, solely, their systemic entry is unwanted but often unavoidable, whereas in case of systemic tissue targeting, this is even required. Most importantly, the accumulation of the nanomaterials in tissues and cells, which either harbour the target of the orally delivered therapeutic protein (and nanoparticles) or serve as unspecific sink for the nanoparticles after their systemic distribution in the whole body, has to be excluded in the long term. Very recent experimental results hint to the exciting possibility that a novel strategy for both oral delivery and tissue targeting in parallel will overcome these potential toxicity issues. It is based on a 'natural' co-translational modification of the therapeutic protein with a glycolipid structure, the covalent coupling to glycosylphosphatidylinositol (GPI).

\section{GPI Proteins - Structure and Synthesis}

GPI represents a typical glycolipidic structure consisting of phosphatidylinositol with long-chain saturated fatty acids which is coupled via a complex glycan core, a terminal phosphoethanolamine bridge and an amide linkage to the carboxy terminus of a subset of (often glycosylated) membrane proteins (fig. 4) [65-68]. Thereby, these GPI-anchored proteins (GPI proteins) are anchored at the surface of eucaryotic cells from yeast to man [69, 70]. Typical transmembrane proteins cross the phospholipid bilayer of biological membranes via one or several stretches of 12-20 hydrophobic amino acids each, which in combination act(s) as membrane anchor(s) (fig. 4) [71, 72]. In contrast, the GPI anchor is inserted in the outer (extracellular) phospholipid monoleaflet of the plasma membrane, exclusively, with preference for special areas, so-called lipid rafts or detergent-insoluble glycolipid-enriched microdomains (DIGs). DIGs are characterized by high concentrations of cholesterol, glycolipids, glycosphingolipids and phospholipids harbouring long-chain fatty acids [73-78]. The resulting rigid lipid environment attracts subsets of transmembrane proteins, such as the caveolins, and the majority of GPI proteins. DIGs formed by the typical membrane phospholipids and proteins float like rafts in the ocean. They have been attributed a multitude of important cellular functions, such as transport of cholesterol, fatty acids and proteins as well as signal transduction across the plasma membrane $[79,80]$. The GPI anchor is susceptible to cleavage by special types of serum phospholipases $\mathrm{C}$ or $\mathrm{D}$ [81-84]. They operate in constitutive or regulated fashion during a number of physiological (for example insulin action [85]) and pharmacological (for example glimepiride action [86, 87]) processes or are used for the experimental release of the (hydrophilic) protein moiety from the membrane or cell surface for the diagnosis of GPI anchorage (fig. 4) [88].

The co-translational coupling of the GPI anchor to the protein moiety during the biosynthesis of GPI proteins requires the presence of two distinct targeting signals, signal sequences I and II, which flank the GPI protein precursor encoded by the relevant susceptibility gene (fig. 5). Signal sequence I at the amino terminus, which is structurally and functionally identical to that operating for the transport in secretory and transmembrane proteins, directs the (still GPI anchor-less) nascent polypeptide chain of the GPI protein for co-translational transfer across the membrane of the endoplasmic reticulum. Signal sequence II at the carboxy terminus, which structurally resembles a proteinaceous transmembrane anchor, 


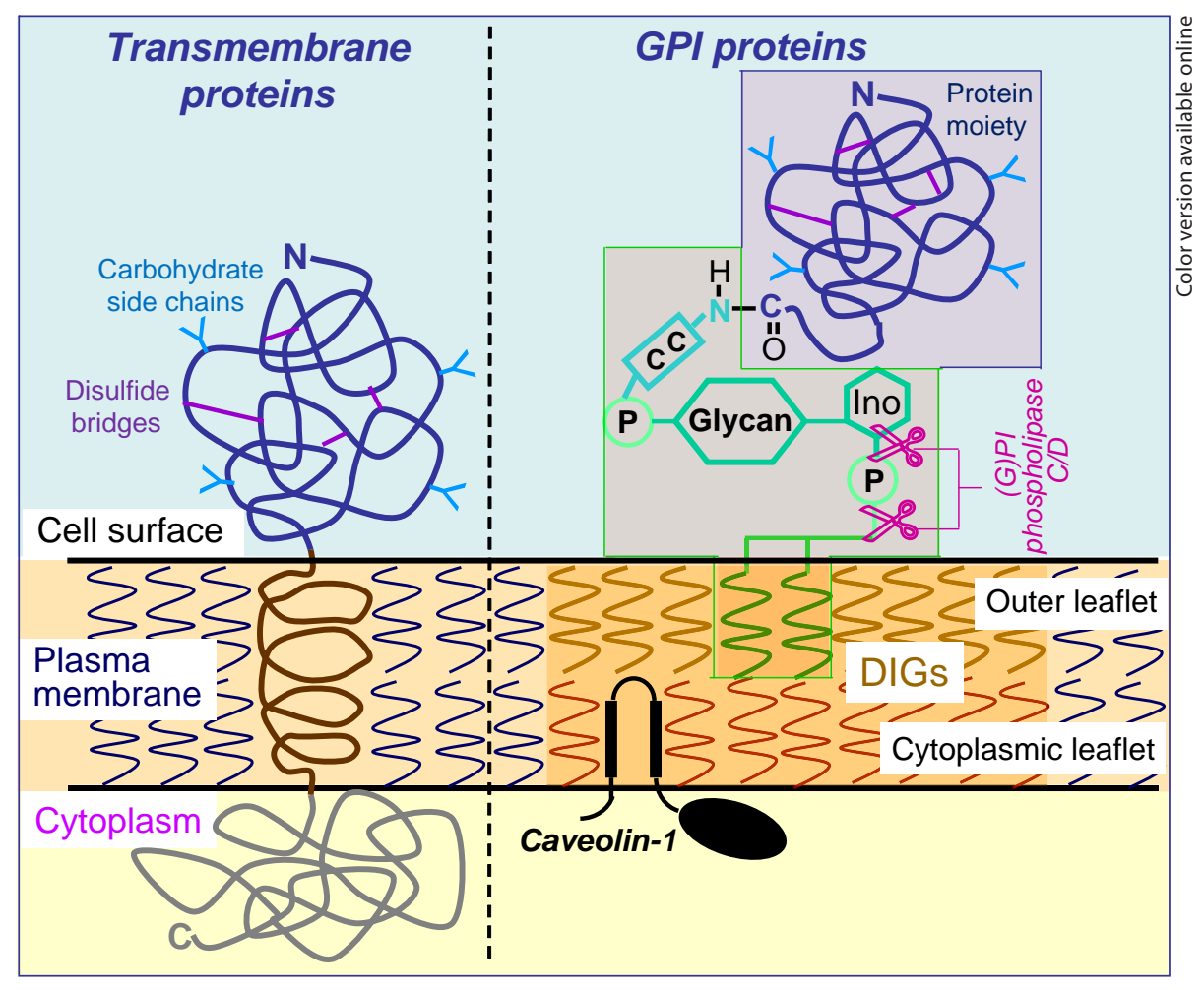

Fig. 4. Structures of two common classes of eucaryotic plasma membrane proteins. Typical transmembrane proteins span the phospholipid bilayer of the plasma membrane with one to several $\alpha$-helical stretches of 12-20 hydrophobic amino acids each (in brown, colour only in online version), thereby directing one to several hydrophilic polypeptide domains to the cell surface (often with disulfide bridges and carbohydrate chains) and to the cytoplasm (always reduced and unglycosylated). The atypical transmembrane protein, caveolin-1, does not span the phospholipid bilayer, but penetrates only into the cytoplasmic leaflet of the plasma membrane with a hook-like hydrophobic segment thereby directing both the terminal small and large polypeptide domains to the cytoplasm. Caveolin-1 is predominantly enriched at the DIGs (see text for details). GPI proteins are anchored in the outer leaflet of the plasma membrane by the GPI glycolipid structure. GPI is built up of phosphoethanolamine, a glycan core consisting of several mannose and non-acetylated glucosamine residues in typical glycosidic linkages, myo-inositol (Ino) and phosphatidic acid equipped with saturated long-chain fatty acids. The GPI anchor is amide-linked to the carboxy terminus of the hydrophilic polypeptide moiety located at the cell surface. Putative cleavages by the (G)PI-specific phospholipases C and D expressed at the plasma membrane of (rat) adipocytes and in (human) serum which result in the generation of diacylglycerol and phosphatidic acid, respectively, and the release of the polypeptide moiety with glycan-phosphate and glycan remnants, respectively. dictates the transient 'stop transfer' of the nascent polypeptide chain. Thereafter, signal sequence II becomes replaced by the GPI anchor (prefabricated at the endoplasmic reticulum membrane by sequential glycosylation of phosphatidylinositol) in the course of a specific transamidation reaction. Subsequently, the completed GPI protein with its GPI anchor embedded in the luminal leaflet of the endoplasmic reticulum membrane is transported along the secretory pathway. Upon final fusion of the secretory vesicles with the plasma membrane the GPI protein moiety becomes exposed at the cell surface with the GPI anchor being inserted into the extracellular membrane leaflet of the DIGs (fig. 5). Meanwhile, the biosyn- thesis of this complex co-translational modification, including all genes which code for the glycosylation enzymes and the transamidase, has been unravelled [68-70, 89 ] and found to be highly conserved from yeast to man. Of critical importance for the use of GPI proteins in therapy is the possibility to convert (almost) each (soluble) protein (of potential therapeutic interest) into its GPI-anchored version [90]. For this, its gene sequence simply has to be coupled to the signal sequences I and II by recombinant DNA manipulation. The biochemical analyses of a number of recombinant fusion proteins with hydrophilic polypeptide domains coupled at their carboxy terminus to GPI anchors of varying fatty acid composition 


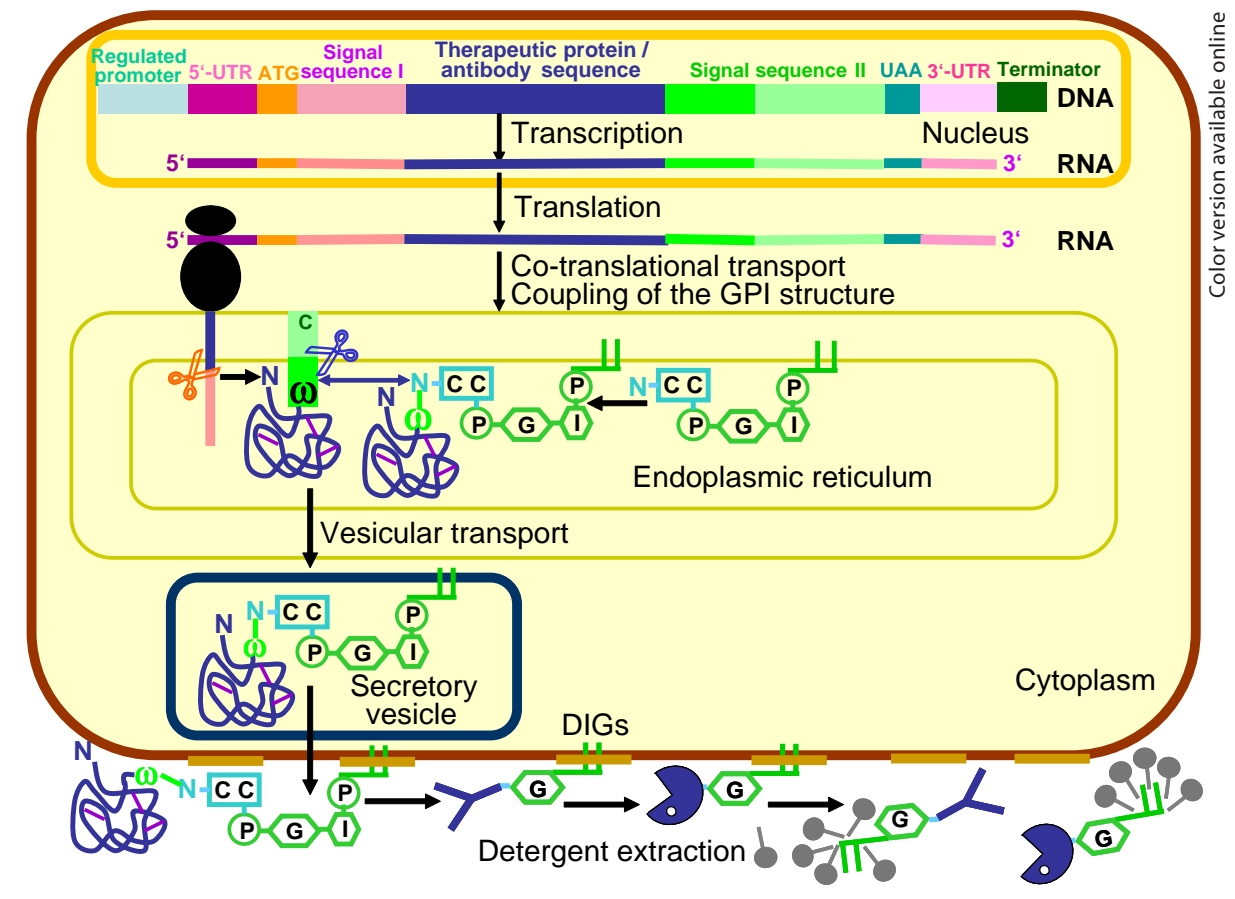

Fig. 5. Biosynthesis and recombinant expression of GPI proteins in eucaryotic cells. The gene encoding the (eventually modified) therapeutic protein or antibody passenger is fused (by recombinant DNA technology) at its $5^{\prime}$-end to the signal sequence I including the start codon and the cleavage site for the signal peptidase (orange scissors, colour only in online version) and at its $3^{\prime}$ end to the signal sequence II, which consists of a hydrophobic transiently membrane-spanning segment (light green) including the transamidase (blue scissors) recognition site $\omega$ and a hydrophilic segment (dark green) including the stop codon. Signal sequences I and II derived from typical secretory proteins and GPI proteins, respectively, are inserted as cassettes into appropriate shuttle vectors (virus or plasmid based) for efficient transfection of yeast (for example Saccharomyces cerevisiae) or mammalian cells (for example CHO, COS, HEK293). Trancription of the passenger sequences is controlled by the upstream located strong (and possibly regulated) promoter in concert with the downstream located terminator, translation by the upstream located $5^{\prime}$-untranslated region ( $5^{\prime}$-UTR) in concert with the downstream located 3 '-untranslated region ( 3 '-UTR). Upon co-translational transport into the endoplasmic reticulum, cleavage of signal sequence I by signal peptidase and cleavage of signal sequence II under concomitant coupling of the passenger protein precursor to the pre-fabricated GPI anchor ( $\mathrm{P}=$ phosphate, $\mathrm{G}=$ glycan, $\mathrm{I}=$ inositol, $\mathrm{C}-\mathrm{C}=$ ethanolamine) by transamidase, the GPI protein is delivered to the plasma membrane by vesicular transport through the cytoplasm and finally inserted into DIGs with the passenger protein moiety facing the cell surface. For therapeutic applications the GPI protein can be extracted from plasma membrane DIGs with non-ionic detergents and reconstituted into detergent micelles using routine procedures. in comparison to those with proteinaceous transmembrane anchors revealed only no to moderate effects of the GPI anchor on the enzymic, binding or signalling functions of the corresponding passenger proteins [91-95]. This might have been unexpected given the previously observed very close proximity of the protein moiety of GPI proteins to the membrane surface [96]. The apparent functional independence of the passenger protein and GPI anchor will facilitate the versatile construction of appropriate therapeutic GPI protein/antibody fusion polypeptides.

Upon transfection of yeast, insect or appropriately cultured mammalian cells with the corresponding viral or plasmid vectors, GPI-anchored fusion proteins will be ex- pressed in high amounts and with considerable enrichment [90] and can be used after preparation of total intact or detergent-solubilized cellular membranes or after their (partial) purification and subsequent reconstitution into liposomes. Moreover, the recombinant ectopic GPI proteins or GPI antibodies can be selectively extracted from the cell surface of the mammalian or yeast host cells by specific non-ionic detergents, such as $\beta$-amidotaurocholate $[97,98]$, and be reconstituted into detergent micelles without the need for further purification to homogeneity (fig. 5). Complexes of GPI fusion proteins and detergents may potentially be used for oral delivery and subsequent transport of therapeutic proteins and antibodies into or 


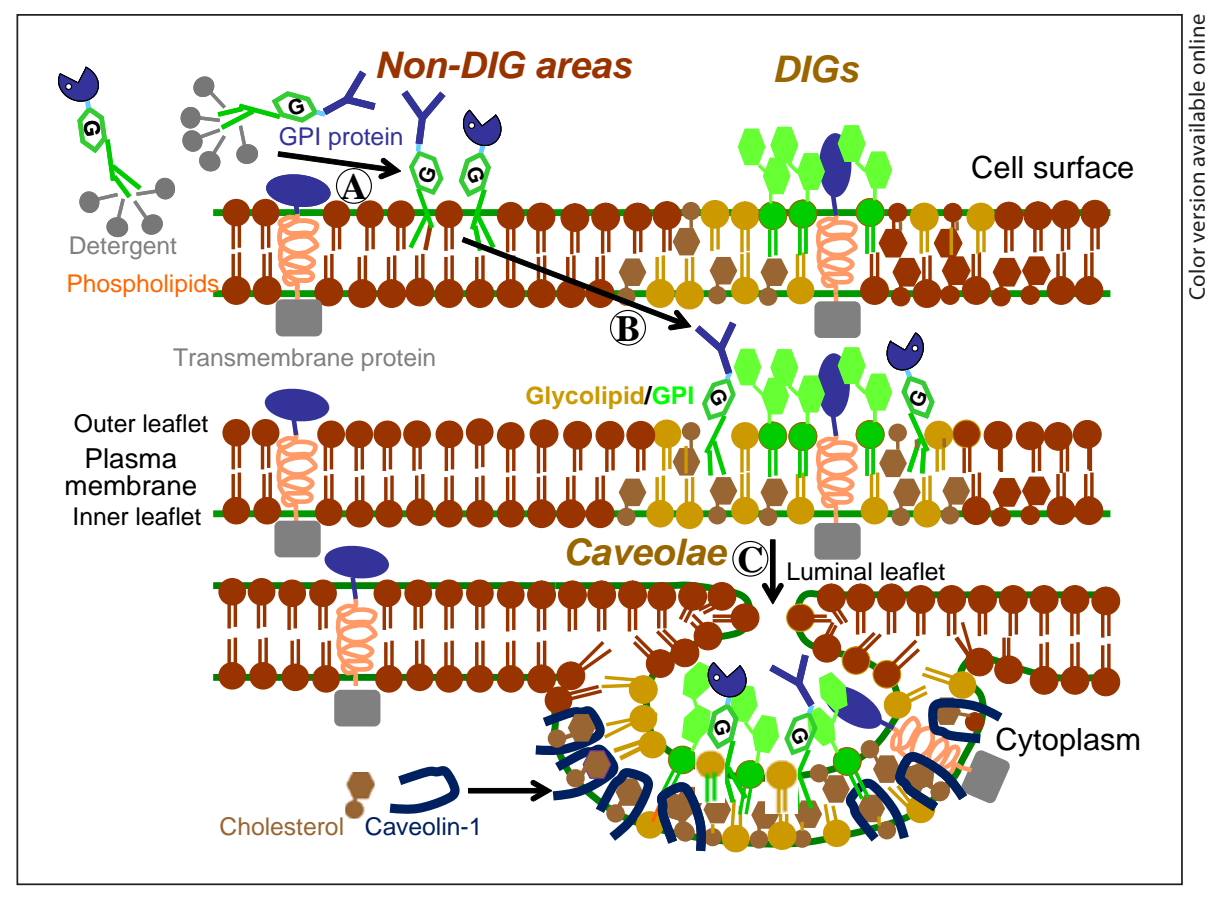

Fig. 6. Model for the transfer of GPI proteins into DIGs and caveolae. Step A: GPI proteins or antibodies reconstituted into detergent micelles and exposed to intact mammalian cells spontaneously insert into the outer (extracellular) leaflet of plasma membrane areas deprived of endogenous GPI proteins, glycolipids and cholesterol (non-DIG areas). Step B: GPI proteins/antibodies (but not transmembrane proteins) undergo time-dependent lateral movement into DIGs enriched in endogenous GPI proteins, glycolipids and cholesterol. Step C: caveolin-1, synthesized as soluble protein in the cytosol, becomes incorporated into the inner (cytoplasmic) leaflet of the DIGs plasma membrane, which is fostered by its affinity to cholesterol. The subsequent

across enterocytes, into the circulation, certain target tissues and the cytoplasm of certain target cells (fig. 3).

\section{Trafficking of GPI Proteins in Adipocytes}

The following recent experimental findings raised by several research laboratories for a variety of cell types different from enterocytes suggest the potential of GPI modification of therapeutic proteins for their oral delivery and, if required, for their subsequent translocation into the cytoplasm of the target tissue cells (fig. 3). Recombinant purified GPI proteins, reconstituted into detergent micelles, spontaneously associate with (target) cells of different origin upon incubation in vitro (fig. 6) [99-107]. The GPI anchor inserted into the outer leaflet of the DIGs oligomerization of the caveolin-cholesterol complexes drives the formation of cave-like invaginations at the DIGs along with the GPI proteins/antibodies and glycolipids at the outer leaflet and a subset of transmembrane proteins which all reside at the DIGs. Completion of the invagination and budding leads to the generation of closed caveolin-coated vesicles, so-called caveolae, with the GPI anchors embedded in luminal leaflet of the caveolar membrane and the GPI protein/antibody moieties facing the caveolar lumen. The underlying molecular mechanism resembles, but is not identical with, endocytosis of non-clathrin-coated vesicles.

plasma membrane mediates anchorage and presentation of the (passenger) protein at the cell surface [99, 107-109]. This so-called 'cell surface painting' has already been used for the ectopic expression of modified antigens (for immunization), receptors (for signal transmission) or binding proteins (for transport) at the cell surface of biotechnologically relevant mammalian cells, which does not rely on (sometimes troublesome) DNA transfection methods $[101,110]$. Importantly, the newly acquired cell surface proteins may undergo transcytosis, that is transcellular transport via the cytoplasm from the apical to the basolateral plasma membrane, in polarized cells or translocation across the plasma membrane into the cytoplasm of both polarized and non-polarized cells (fig. 3). It is well established that DIGs, which per se appear as 'flat' structures, can form invaginations oriented toward the cyto- 


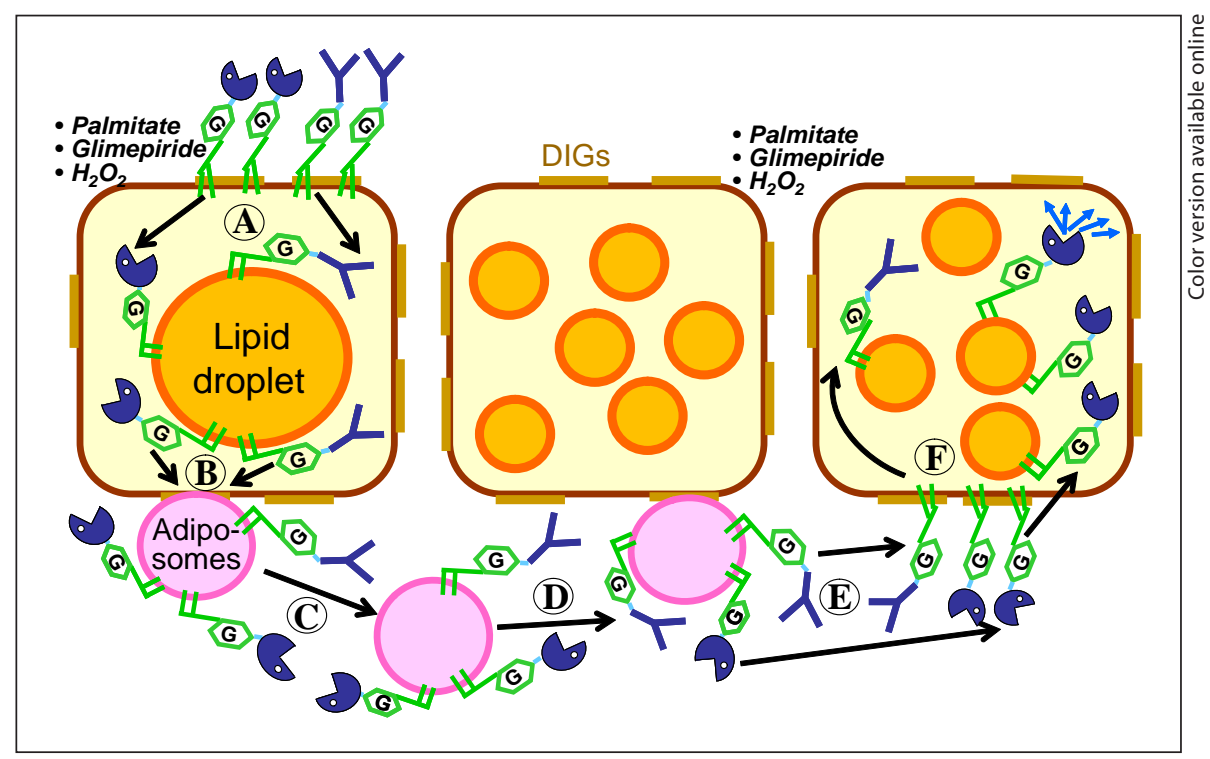

Fig. 7. Model for the intra- and intercellular trafficking of GPI proteins within adipose tissue. Step A: GPI proteins or antibodies enriched at plasma membrane DIGs of adipocytes are translocated to the surface of LD via embedding of their GPI anchors in the LD phospholipid monolayer. Step B: subsequently, they become associated with adiposomes, presumably emerging at plasma membrane DIGs (light brown lines, colour only in online version), via embedding of their GPI anchors in the outer leaflet of the adiposome phospholipid bilayer. Step C: the adiposomes harbouring the GPI proteins are released from the (preferably large) donor adipocytes. Step D: the adiposomes circulate within the same or between distinct adipose tissue depots and come into contact with plasma membrane DIGs of (preferably small) accep- tor adipocytes. Step E: this triggers the transfer of the GPI protein cargo of the adiposomes to the DIGs via embedding of their GPI anchors in the outer leaflet of the DIGs phospholipid bilayer. Step F: subsequent translocation of the GPI proteins and antibodies to the surface of LD via embedding of their GPI anchors in the LD phospholipid monolayer leads to cytoplasmic orientation of their catalytic and antigen-binding protein moieties, respectively. Translocation of the GPI proteins from DIGs to LD in both donor and acceptor adipocytes (steps A and F) as well as the release of the adiposomes (step B) are positively controlled by certain exogenous physiological (palmitate, $\mathrm{H}_{2} \mathrm{O}_{2}$ ) and pharmacological (glimepiride) signals. plasm. Upon synthesis of the atypical transmembrane protein, caveolin-1, its post-translational insertion into and both homo- and heterooligomerisation and complex formation with cholesterol within the cytoplasmic leaflet of the DIGs membrane bilayer [111-115] trigger the budding of closed vesicles, so-called caveolae, from the plasma membrane into the cytoplasm (fig. 6).

Transcytosis of GPI proteins in polarized cells (for example endothelial cells, enterocytes, epithelial cells) and their reported preferential targeting to either the apical or basolateral plasma membranes [116-118] may be mediated by caveolae harbouring the GPI proteins at their luminal face in the course of their partial or complete nonclathrin- but caveolin-mediated endocytosis [119-121]. The underlying molecular mechanisms may encompass the lateral diffusion of the GPI proteins along the luminal leaflets of tubular membrane structures formed by the fused caveolae [122]. These could transverse the cyto- plasm and connect the apical and basolateral plasma membranes. Alternatively, distinct non-fusing caveolar vesicles may carry the luminal GPI protein across the cytoplasm from the extracellular leaflet of the apical plasma membrane to that of the basolateral plasma membrane upon their budding and fusion, respectively $[115,123$, 124]. With both mechanisms the transcellular transport of GPI proteins will result in their anchorage at the surface (in DIGs) of the basolateral membrane of enterocytes or endothelial cells oriented towards their underlying interstitial tissue spaces.

The previously demonstrated translocation of GPI proteins from plasma membrane DIGs into the cytoplasm of non-polarized cells, such as adipocytes, occurs constitutively, but at a low rate, and becomes significantly up-regulated in response to physiological (such as palmitate, $\mathrm{H}_{2} \mathrm{O}_{2}$ ) or pharmacological (such as anti-diabetic sulfonylurea glimepiride) stimuli (fig. 7; step A) [125- 
127]. In the course of translocation, GPI proteins previously residing at plasma membrane DIGs or caveolae of adipocytes appear in highly enriched fashion at the surface of cytoplasmic lipid droplets (LD) $[128,129]$. LD act as the storage organelles for triacylglycerols, which represent hydrophobic, highly reduced and concentrated carriers of energy [130-132]. Thus, energy storage is compartmentalized in LD in eucaryotic cells, in general. In adipocytes, the most highly specialized cells dedicated to store energy, LD often occupy the bulk of the cytoplasm. In mammals, energy storage and catabolism in LD is highly regulated by the nutritional state and hormones via engagement of downstream signalling pathways. The triacylglycerols are deposited together with cholesterylesters in the core of the LD, which is surrounded by a phospholipid monolayer with intercalated free fatty acids as well as cholesterol and decorated with specific proteins, such as perilipin-A [130-132]. In addition to compartmentalized energy storage, LD are involved in intracellular protein storage and metabolism. For instance, during development of the fruit fly Drosophila, histones accumulate at the surface of LD until their successful import and complexing to DNA in rapidly dividing nuclei [133]. During replication of the hepatitis $C$ virus in infected humans, its core protein also localizes to LD in hepatocytes $[134,135]$. LD also has been linked functionally to the spliceosome and proteasome $[132,133,136,137]$. Thus, LD might serve as platforms for the coordination and regulation of deposition and degradation of various types of proteins, among them membrane proteins, nuclear proteins and soluble proteins of both endogenous and exogenous origin, in addition to mere energy storage.

Very recently, two GPI proteins, Gcel and CD73, have been found associated with LD of rat adipocytes. They are anchored at the LD surface through insertion of their GPI fatty acyl chains into the LD phospholipid monolayer and expose their protein moiety toward the cytoplasm (fig. 7; step A) $[128,129]$. The molecular mechanisms responsible for this atypical topological reorientation of GPI proteins from the extracellular/luminal to the cytoplasmic localization (which apparently does not fit the rules of vectorial vesicular transport along the classical secretory pathway) remain to be elucidated. They may be based on a novel specialized type of endocytosis with subsequent vesicular trafficking to the endoplasmic reticulum where the de novo biogenesis of LD with accompanying assembly of the reoriented GPI proteins at the cytoplasmic face of the endoplasmic reticulum membrane takes place (fig. 8). Alternatively, the involvement of micellar or bicellar structures which are formed within the DIGs and consist of GPI proteins, phospholipids, glycolipids and additional proteins (for example those destined for removal and degradation during quality control) [138] is conceivable (fig. 8). These structures may represent primordial LD prior to their filling with triacylglycerol and cholesterylester.

\section{Trafficking of GPI Proteins between Adipocytes}

Unexpectedly, in rat adipocytes LD-associated Gcel and CD73 were found to be redirected from the LD to small vesicles, so-called adiposomes, and thereby to be released into the incubation medium during pulse-chase experiments (fig. 7; step B) [127]. The GPI anchor of Gcel and CD73 becomes embedded in the extracellular leaflet of the adiposomal phospholipid bilayer and the protein moieties exposed at the adiposomal surface [139, 140]. These adiposomes resemble the well-characterized microvesicles and exosomes harbouring subsets of transmembrane [141-143] and GPI proteins [82, 139, 144], which are released from most mammalian cells into the circulation in vivo or into the incubation medium in vitro. The release of microvesicles following plasma membrane blebbing or shedding as well as of exosomes following plasma membrane fusion, that is exocytosis, of so-called multivesicular bodies, which both presumably occur at plasma membrane DIGs [142-156], is either constitutive [145] or upregulated by cellular activation or apoptosis [146-148]. In general, microvesicles and exosomes are assumed to operate as vehicles for the transfer of information-carrying proteins, among them GPI proteins, from donor to acceptor cells. Thereby, information is transferred in horizontal fashion which may be related to a multitude of physiological and pathophysiological functions, such as apoptosis induction, correction of paroxysmal nocturnal haemoglobinuria, control of blood coagulation and platelet activation, propagation of prion protein or tumour metastasis [145-169]. Similarly, adiposomes in concert with the surface-exposed GPI proteins are released from (preferably large) donor adipocytes in moderate and constitutive and, more potently, regulated fashion (by the same signals which elicit the translocation of GPI proteins from the cell surface to the LD surface, see above) (fig. 7; step C) and become associated (in spontaneous and constitutive fashion) with plasma membrane DIGs of (preferably small) acceptor adipocytes (fig. 7; step D) $[139,140]$. Subsequently, the GPI proteins are transferred from these bound adiposomes to DIGs during a 


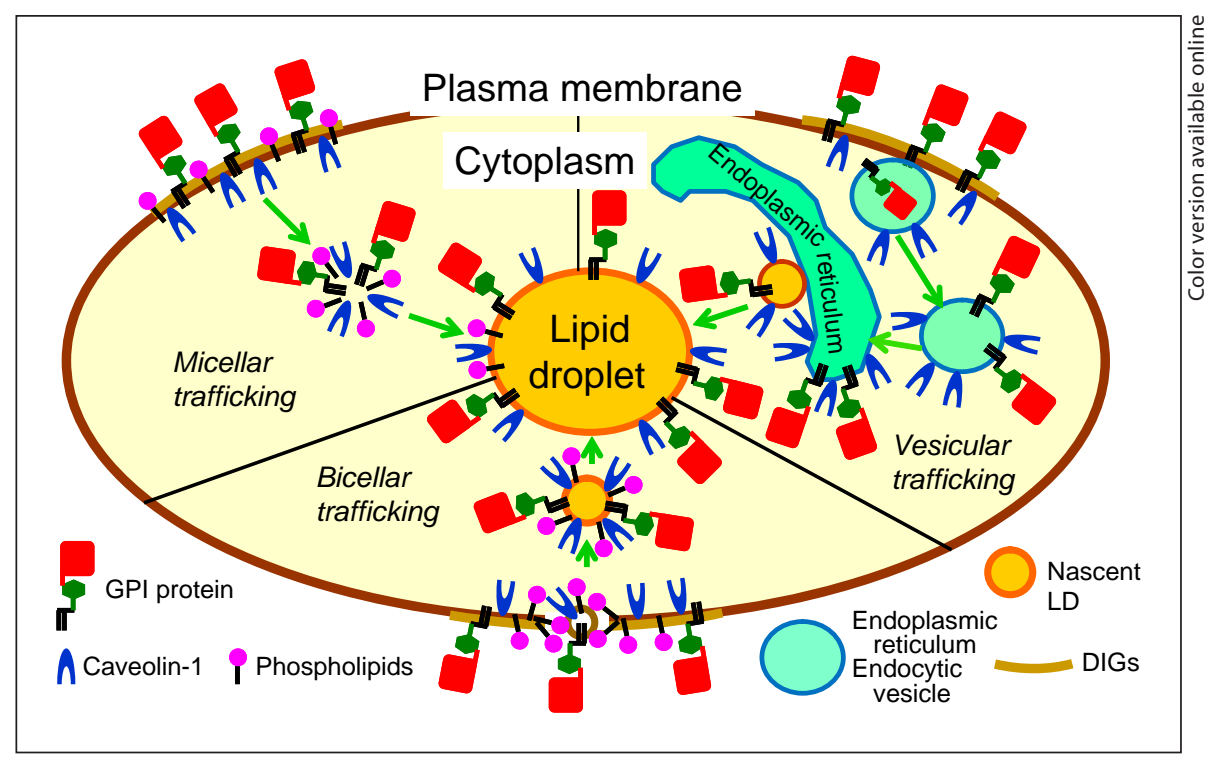

Fig. 8. Three putative mechanisms for the intracellular trafficking of GPI proteins from DIGs to LD. In the model of micellar trafficking, micelles consisting of phospholipids, caveolin-1 and the GPI proteins are formed at the DIGs (light brown, colour only in online version) of the plasma membrane (dark brown), which then escape from the DIGs, move through the cytoplasm and finally deliver their cargo GPI protein to the LD, possibly by spontaneous insertion into their phospholipid monolayer (orange). In the model of vesicular trafficking, GPI proteins in concert with caveolin-1 are internalized by (non-clathrin-coated) endocytic vesicles forming at the DIGs with their protein moieties (red) facing the vesicle lumen. During subsequent movement of the endocytic vesicles through the cytoplasm and their fusion with the endoplasmic reticulum, reorientation of the GPI proteins by a 'flip-flop' mechanism leads to inversed topology with their protein moieties facing the cytoplasm and their GPI anchors embedded in the cytoplasmic leaflet of the endoplasmic reticulum bilayer. The de novo biogenesis of LD at these sites of the endoplas- mic reticulum with budding of the cytoplasmic membrane leaflet will drive the integration of typical LD-associated proteins, such as perilipin and caveolin-1, as well as of the atypical LD-associated GPI proteins into the phospholipid monolayer surrounding the nascent $\mathrm{LD}$. These increase in size and grow to mature LD by the synthesis and incorporation of triacylglycerol and cholesterylesters into the LD core (orange). In the model of bicellar trafficking, small phospholipid micelles harbouring GPI proteins and caveolin-1, so-called bicelles, are transiently formed at DIGs leaving 'plasma membrane holes' with sealing 'phospholipid edges'. Subsequently, the bicelles are released from the DIGs into the cytoplasm under concomitant closure of the 'plasma membrane holes' and then sequentially converted into nascent and mature LD as described for the vesicular trafficking model. Irrespective of the molecular mechanism, the trafficking has been demonstrated to operate constitutively at low rate, but to be significantly up-regulated by exogenous physiological (for example palmitate, $\mathrm{H}_{2} \mathrm{O}_{2}$ ) and pharmacological (for example glimepiride) signals. spontaneous and constitutive process that depends on the integrity of both the GPI anchors and the DIGs and remains restricted to subsets of transmembrane proteins and GPI proteins (fig. 7; step E). Thereafter, the transferred GPI proteins are translocated in the absence or, more potently, presence of exogenous signals (palmitate, glimepiride, $\mathrm{H}_{2} \mathrm{O}_{2}$ ) from the plasma membrane DIGs to the intracellular LD of the acceptor adipocytes (fig. 7; step F). This translocation of exogenous GPI proteins seemingly parallels that of their endogenous GPI protein counterparts and finally leads to GPI anchorage at the surface monolayer of $\mathrm{LD}$ with the protein moieties facing the cytoplasm.

This complex inter- and intracellular trafficking of GPI proteins has recently been demonstrated for the ad- iposome-mediated transfer of the GPI-anchored (c)AMPdegrading enzymes, Gcel and CD73, from donor to acceptor adipocytes and their subsequent translocation to cytoplasmic LD of the acceptor adipocytes [170-172]. The expression of Gcel and CD73 at the LD surface with their (c)AMP-degrading catalytic domains gaining access to the cytoplasm leads to lowering of the concentration of (c)AMP at the LD surface zone (fig. 9). The resulting blockade of cAMP-dependent phosphorylation causes the inhibition of hormone-sensitive lipase and activation of glycerol-3-phosphate acyltransferase in the immediate vicinity of the LD [170-172]. Thus, this mechanism coordinates down-regulation of lipolysis and up-regulation of esterification which both ultimately foster triacylglycerol 


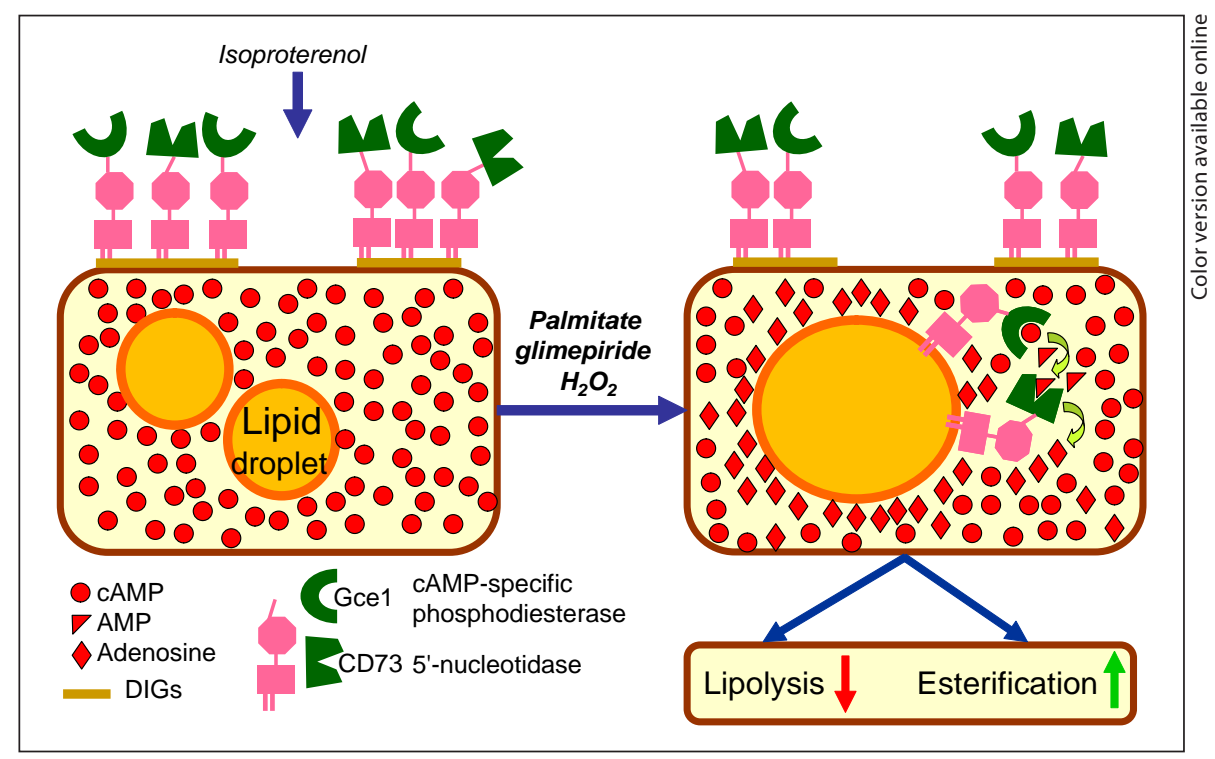

Fig. 9. Model for the involvement of intra-adipocyte trafficking of the GPI proteins, Gcel and CD73, for the regulation of lipid metabolism. $\beta$-Adrenergic challenge of adipocytes with isoproterenol increases total cytoplasmic cAMP leading to stimulation of lipolysis, the release of fatty acids from triacylglycerol, and inhibition of esterification, the incorporation of fatty acids into triacylglycerol. Exogenous signals, such as palmitate, glimepiride and $\mathrm{H}_{2} \mathrm{O}_{2}$, promote the translocation of $\mathrm{Gcel}$ and CD73 from plasma membrane DIGs (light brown lines, colour only in online version) to LD. The resulting cAMP-to-adenosine conversion and lowering of the cAMP levels at the LD surface zone by the concerted actions of the cAMP-specific phosphodiesterase activity of Gce1 and 5'-nucleotidase activity of CD73 cause inhibition of lipolysis and stimulation of esterification with concomitant upregulation of LD biogenesis and adipocyte differentiation. synthesis and LD biogenesis. As a consequence, information about (c)AMP-dependent signalling and metabolic pathways, such as the stimulation of esterification and inhibition of lipolysis, is transmitted between physiologically distinct (large and small) adipocyte subpopulations within the same (for example subcutaneous) tissue depot (that is, in paracrine fashion) or between different (for example subcutaneous and visceral) depots (that is, in endocrine fashion). Thus, in adipose tissue communication via adiposomes seems to signal the shift of burden of lipid loading from large 'old' to small 'young' adipocytes (fig. 7) and may trigger LD biogenesis and differentiation of pre-adipocytes $[5,170]$.

\section{DIGs and LD as Common Denominators between Adipocytes and Enterocytes}

More than $95 \%$ of dietary fat consumed is absorbed whether a low- or high-fat diet is consumed [173], as evidenced by the small amount of fat that is excreted in faeces in either case. In the small intestine lumen, dietary fat in the form of triacylglycerol is hydrolyzed to generate free fatty acids and monoacylglycerol by pancreatic lipase. These cleavage products are then emulsified with the help of phospholipids and bile acids present in bile to form micelles. Both free fatty acids and monoacylglycerol are then taken up by the absorptive cells of the small intestine, the enterocytes, where they are re-synthesized into triacylglycerol and incorporated into the core of chylomicrons which are secreted via the lymphatic system into the circulation $[174,175]$. Surprisingly, wild-type mice fed a high-fat diet or challenged with an oil bolus by oral gavage are commonly reported as having no LD accumulation in enterocytes [176-178]. Nevertheless, both indirect and direct evidence exists supporting the presence of a cytoplasmic triacylglycerol storage pool in enterocytes. In humans, sequential meal tests demonstrated that chylomicrons secreted after a second meal carried triacylglycerol ingested during the first meal $[179,180]$. In rats, triacylglycerol is synthesized within $30 \mathrm{~s}$ after an intraduodenal fat infusion [181]. However, the secretion of triacylglycerol into the lymph does not reach a steady state until $4 \mathrm{~h}$ after infusion, suggesting that the rate-lim- 
iting step in dietary fat absorption is the transport of triacylglycerol from the endoplasmic reticulum to the Golgi apparatus [182]. This led the investigators to hypothesize that during this period, triacylglycerol resides on the cytoplasmic leaflet of the endoplasmic reticulum membrane for later secretion [183]. In addition, more triacylglycerol was found in the cytoplasm of enterocytes prepared from high fat-fed compared to chow-fed rabbits by biochemical analysis [184]. Finally, electron microscopy images of enterocytes from humans challenged with fat loads demonstrated the existence of a cytoplasmic triacylglycerol storage pool [185]. Re-synthesized triacylglycerol, which first enters a cytoplasmic storage pool, may not be immediately available for the synthesis of chylomicrons. However, upon lipolysis and re-esterification it may then enter the lumen of the endoplasmic reticulum where the assembly of chylomicrons begins. Nevertheless, whether a dynamic cytoplasmic pool of triacylglycerol and, in consequence, LD exists during the process of dietary fat absorption has remained controversial so far [186].

However, very recently the presence of LD in enterocytes has been demonstrated on the basis of resonant coherent anti-Stokes Raman scattering microscopy signals from symmetric $\mathrm{CH}_{2}$ stretch vibration [187]. The nature of the LD was confirmed by biochemical analysis to predominantly consist of triacylglycerol. Combined coherent anti-Stokes Raman scattering microscopy and fluorescence imaging showed that these LD were located in the cytoplasm and coated with the LD-specific PAT protein TIP47 [188]. The amount of triacylglycerol stored in the enterocytes was found to be highly dependent on the region of the intestine and directly correlated with the amount of fat consumed. Moreover, the recent observations of LD in ex vivo fresh intestinal tissues provided direct evidence that dietary free fatty acids enter a dynamic cytoplasmic triacylglycerol pool in enterocytes in response to a dietary fat challenge [187]. Together the results highlight the dynamics of the cytoplasmic triacylglycerol pool in enterocytes which may have evolved to insure the absorption of highly energy-dense macronutrients during times when food was scarce [187]. Mammalian enterocytes are constantly renewing and turn over every 3-4 days. Thus, mammalian enterocytes would not be considered a long-term storage depot for triacylglycerol, as mammals have adipose tissue to serve this purpose. Nonetheless, the temporal storage of triacylglycerol in enterocytes allows its excess after a meal rich in dietary lipid to be conserved within the cell as opposed to being excreted in faeces. The storage of triacylglycerol in LD of enterocytes after a meal rich in dietary fat may also alleviate lipotoxicity to enterocytes by high concentration of free fatty acids [189]. Based on these data, a revised model of triacylglycerol metabolism within enterocytes has been proposed to depict the physiological role of LD in enterocytes during dietary fat absorption. This model is consistent with previous models describing triacylglycerol storage and secretion in hepatocytes and enterocytes [186]. In this model diacylglycerol is synthesized from the products of dietary fat digestion, monoacylglycerol and fatty acylcoenzyme A. Triacylglycerol is then synthesized from diacylglycerol and fatty acyl-coenzyme A. In enterocytes the synthesized triacylglycerol has 2 potential fates: direct incorporation into nascent chylomicrons for immediate secretion via the Golgi apparatus or storage in cytoplasmic LD. It should be noted that the existence of a cytoplasmic triacylglycerol pool has been well accepted for hepatocytes where triacylglycerol is recycled and secreted in the form of very low-density lipoprotein $[186,190]$.

\section{Hypothetical Model for Trafficking of GPI Proteins across Enterocytes}

Albeit experimental data are lacking so far, enterocytes may behave similar to adipocytes with regard to inter- and intracellular trafficking of GPI proteins. This assumption seems to rely on a sound basis given the known high contents of plasma membrane DIGs [191, 192] and LD [187] in rodent enterocytes. Consequently in analogy to adipocytes, for enterocytes the following multi-step model for the oral delivery of therapeutic proteins and antibodies in the course of transcellular transport and/or translocation onto the surface of cytoplasmic $\mathrm{LD}$ and subsequent release via microvesicles/exosomes and translocation into the cytoplasm of acceptor cells can be envisaged. It is based on the unique property of GPI proteins to associate through their GPI anchor with detergent micelles, plasma membrane DIGs, LD and microvesicles/exosomes in a fashion compatible with interand intracellular trafficking as well as physiological function (fig. 3).

Step 1: following oral ingestion of $\mathrm{pH}$-sensitive filmor gel-coated microspheres (for protection against low $\mathrm{pH}$ and proteases/glucosidases in the stomach, see above) encapsulating appropriately formulated mixed micelles of detergent and the therapeutic GPI fusion proteins/antibodies of interest, the GPI protein load will be released in the intestinal lumen. Thereafter, the GPI proteins will spontaneously insert into DIGs of the apical plasma 
membrane of intestinal enterocytes. Step 2: the GPI proteins are translocated from the DIGs to the surface of cytoplasmic LD of the enterocytes. Step 3: the GPI proteins are then translocated from the LD to DIGs of the basolateral plasma membrane or, alternatively, to multivesicular endosomal bodies for initiation of the biogenesis of microvesicles and exosomes, respectively. Both translocation steps are stimulated by exogenous signals, such as palmitate, glimepiride or $\mathrm{H}_{2} \mathrm{O}_{2}$. In case of missing translocation of the GPI proteins to microvesicles/exosomes, they will remain associated at the LD surface and may fulfil (the desired) physiological (for example enzymic or neutralizing) function directed toward a cytosolic target or mechanism. Step 4: upon completion of shedding of the microvesicles or exocytosis of the multivesicular bodies from the basolateral plasma membrane, the vesicle-associated GPI fusion proteins/antibodies become distributed via the circulation. Step 5: in case of the therapeutic protein/antibody exerting an extracellular function in the circulation (for example as enzyme or neutralizing antibody) or in the interstitial spaces of the target tissue (for example as ligand for cell surface receptors), its release from the circulating microvesicles/exosomes may or may not be necessary (depending on the protein's nature, such as size, surface charge, steric hindrance by GPI) to ensure access to interacting proteins, co-factors or substrates in the blood or to allow free diffusion and transport to the relevant extracellular matrix. GPI anchors are cleaved specifically by (G)PI-specific phospholipases (fig. 4), among them serum phospholipase D, which may provoke lipolytic release of therapeutic proteins/antibodies from GPI anchorage at circulating microvesicles/exosomes. Phospholipase D is highly expressed in human serum $[82,84]$, albeit its efficacy toward GPI anchors embedded in intact membranes of microvesicles/exosomes remains to be clarified [193, 194]. Nevertheless, human GPI-specific phospholipase D represents a candidate enzyme for the last step in the transcellular transport of a therapeutic GPI fusion protein/antibody from the intestinal lumen into the circulation and its conversion from the amphiphilic into its hydrophilic version. Step 6: in case of the therapeutic protein/antibody exerting a function in the cytoplasm of the target tissue cells (for example as signalling protein or neutralizing antibody), the lipolytic release has to be reduced or completely prevented. This could be achieved by alteration of the putative cleavage site for the GPI-specific phospholipase D within the GPI anchor by site-directed mutagenesis of glycosylation enzymes involved in the biosynthesis of the GPI glycan core at the endoplasmic reticulum in the recombinant host cells used for the GPI protein production (fig. 5).

The model proposed for the intracellular and intercellular transport of GPI proteins across enterocytes and from enterocytes to target tissue cells, respectively, is currently based on findings obtained with adipocytes, exclusively, and is therefore of hypothetical nature. However, its relevance for the oral delivery of therapeutic proteins/ antibodies and their subsequent targeting to the plasma or to the cytoplasm of tissue cells can now be studied in vitro and in vivo. Appropriate test models include the passage of GPI fusion proteins (preferably equipped with easily measurable reporter enzymes) from the apically to the basolaterally oriented incubation medium of cultured intestinal epithelial cells and the systemic delivery of GPI hormones (such as GPI insulin) upon their oral administration to appropriate animal models of the disease (such as diabetic rodents) and analysis of the corresponding physiological effect (such as blood glucose decrease).

\section{Trafficking of GPI Proteins beyond Enterocytes and Adipocytes}

The recently reported observations with adipocytes $[171,172]$ raised the possibility for the operation of similar mechanisms of inter- and intracellular trafficking of GPI proteins between and in other tissue cells, such as pancreatic $\beta$, muscle or liver cells, with their transfer from microvesicles/exosomes to plasma membrane DIGs and subsequent translocation to the surface of cytoplasmic LD. Both DIGs and LD are present in virtually all mammalian cell types studied so far, albeit at considerably varying amounts [73-79, 130-132, 195, 196]. The subcellular location at the LD surface enables the therapeutic protein/antibody to substitute for missing or subnormal activity or to dampen hyperactivity of a gene product encoded by a polymorphic/mutant susceptibility gene (fig. 1). Moreover, during the past few years LD have been recognized as a complex, well-organized and dynamic organelle exerting a multitude of important and heterogenous functions (see above) rather than being a simple and static lipid-filled balloon with mere storage capabilities for fatty acids and cholesterol in both adipose and non-adipose cells (fig. 10) [133]. The apparent role of LD in the specific retention and release of regulatory and structural proteins, such as those involved in the intracellular replication of several infectious agents, including Chlamydia and hepatitis $C$ virus $[134,137]$, suggests new therapeutic options for a variety of common diseases, including infec- 


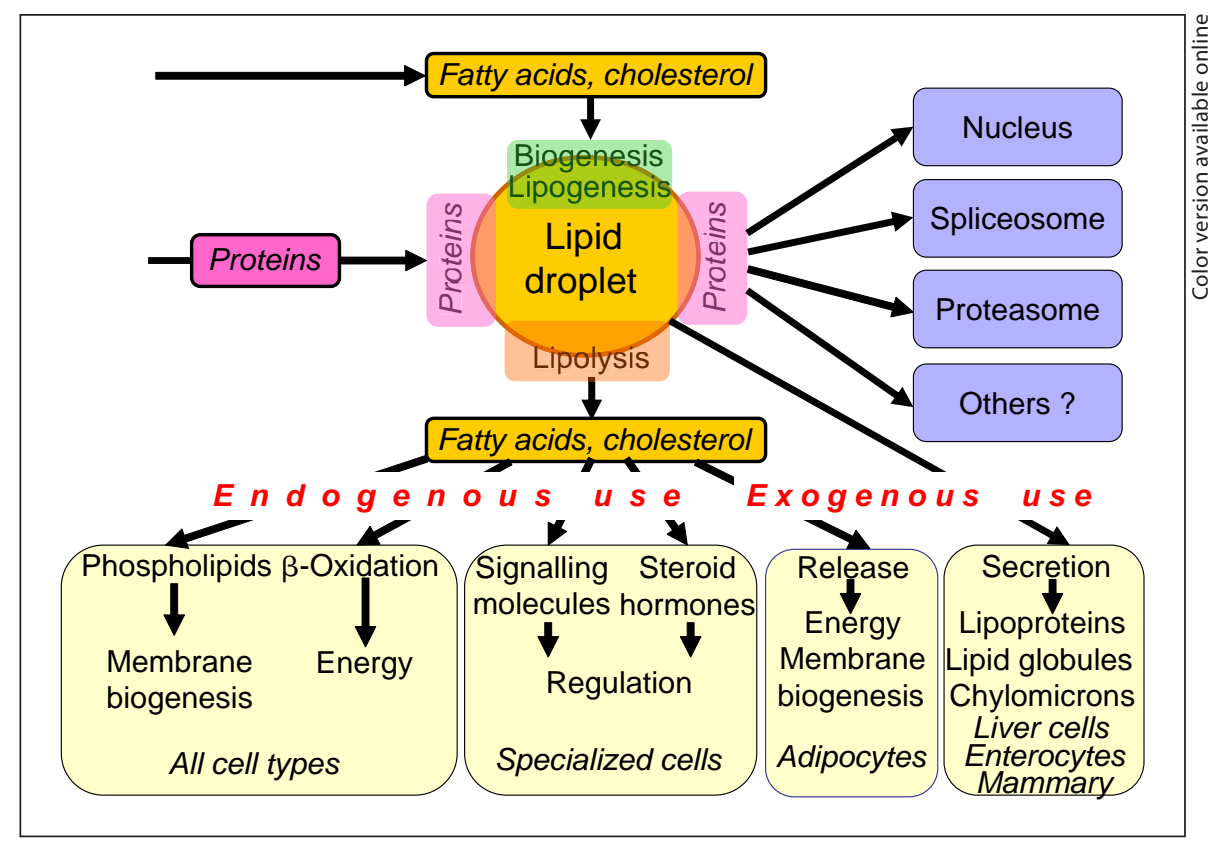

Fig. 10. Multiple functions of LD. LD are heavily engaged in the regulated uptake, esterification and lipolytic release of fatty acids and cholesterol for a multitude of both endogenous and exogenous uses, which are predominantly related to the compartmen- talization of both energy and building blocks for the biosynthesis of membranes and signalling molecules, in a variety of adipose and non-adipose cells. In addition, LD seem to fulfil important roles in the storage and controlled release of proteins. tions. Consequently, this enlarged 'portfolio' of LD could make themselves and the molecular mechanisms underlying their biogenesis, in general, as well as the inter- and intracellular trafficking of GPI proteins to LD, in particular, attractive as drug targets for therapeutic proteins and antibodies with regard to a variety of common complex diseases (fig. 11). In addition to infection and metabolic disorders, such as obesity and type II diabetes, the candidates for potential future therapies with LD-targeted GPI proteins and antibodies encompass cardiovascular diseases, cancer, Alzheimer's disease and aging.

Most important for future progress will be the 'proof of this concept' with intestinal epithelial cells, in general, and with relevant target tissue cells, in particular, including the demonstration of its superior efficacy compared to non-oral and alternative oral (and so far only experimentally used) application routes. Moreover, a number of potential safety issues have to be addressed adequately. Among them is the potential immunogenicity caused by single or few carbohydrate, phosphate or amino acid residues left at the carboxy terminus of the released therapeutic protein/antibody upon cleavage of its GPI anchor by serum phospholipases, phosphodiesterases, glucosidases or proteases. Moreover, in vivo the time course of cleavage and release from microvesicles/exosomes of the therapeutic GPI proteins/antibodies may critically affect the onset and duration of their physiological actions.

In general, for oral delivery of protein therapeutics to become reality for patients suffering from chronic diseases, such as type II diabetes, there are a number of important challenges that need to be addressed irrespective of the technology applied [197-200]. First, long-term efficacy and safety need to be demonstrated through adequately powered studies in different patient populations across the spectrum of the disease. Reproducible absorption of the protein drug and understanding of meal-related absorption are clearly important goals for developing a drug that needs to be administered life-long. Second, clinical studies need to demonstrate superiority over injectable regimens of the protein drug as well as over orally available small-molecule drugs. As an example, for oral insulin the therapeutic goals are improved hypoglycaemic profile, reduced weight gain and, in general, better disease progression outcome in long-term studies in comparison to short-acting injectable human insulin and metformin pills. Third, one of the important open points of long-term protein delivery through the oral route is its potential for inducing mitogenic changes in the gut mu- 


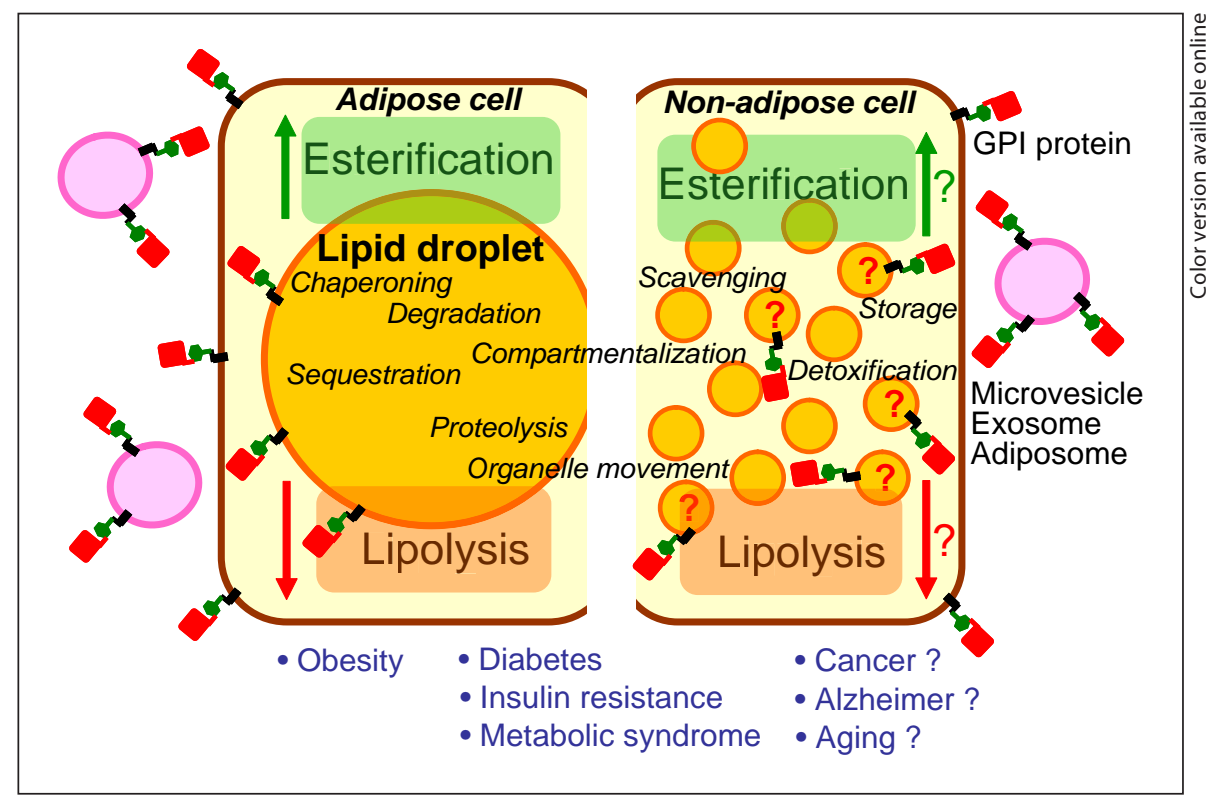

Fig. 11. LD as putative drug targets. During the past decade, LD have been recognized as intracellular organelles fulfilling multiple functions in the storage, chaperoning and degradation of macromolecules. Among them are regulatory and vesicular trafficking proteins controlling the storage, scavening and detoxification of lipophilic (toxic) substances, the retention, release and movement of organelles, the subcellular compartmentalization and the cell surface exposure as well as release into microvesicles and exosomes of metabolic enzymes and signalling proteins, such as the GPI proteins, Gcel and CD73, in both adipose and non-adipose cells. The biogenesis of the LD with concomitant upregulation of esterification and downregulation of lipolysis and, in conse- quence, the LD-mediated physiological functions, such as the release of proteins into microvesicles and exosomes, are controlled by expression of the relevant proteins at the LD, such as the GPI proteins Gcel and CD73. Vice versa, the LD expression of proteins is affected by the LD biogenesis. In adipose cells, the role of LD has been clearly established for the pathogenesis of certain common complex diseases, such as obesity and type II diabetes. In non-adipose cells novel functions have been suggested for LD, such as during tumorigenesis and aging, but have to be confirmed by rigorous experimentation for the validation of LD as future drug target. cosa. For instance, insulin as being an, albeit mild, growth promoter has always been under scrutiny for this potential toxicity issue. This would need to be addressed in long-term toxicity studies. Fourth, the success of oral protein drug delivery depends on the ability to manufacture the (for example GPI-modified) protein both in sufficient quantities for oral delivery as well as efficiently in a cost-conscious pharmaceutical marketplace. If all these issues are successfully addressed, a treatment paradigmchanging therapy of chronic diseases with oral delivery of protein drugs may be the result.

\section{Conclusions}

Taken together, the technology of glycolipid-based, that is GPI-modified, therapeutic proteins/antibodies in combination with special formulations, such as $\mathrm{pH}$-sen- sitive gels, detergent micelles and nanoparticles, could enable the efficient oral delivery of protein drugs and their targeting to the sites of action of the corresponding abnormal gene products encoded by polymorphic/mutant susceptibility genes. No doubt, overcoming the known hurdles will be challenging, but this is presumably a prerequisite for achieving the goal of personalized prevention and therapy of multifactorial complex common diseases in the medium term. Ideally, they will encompass patient-tailored combinations of GPI proteins/ antibodies which address as many as feasible of the products affected by the susceptibility genes in a tissue-specific fashion. GPI proteins and antibodies may thus increase the number of druggable targets, which so far resist attack by small molecules, as well as the number of drugs, which exhibit exquisite specificity toward their target. 


\section{References}

1 Prokopenko I, McCarthy MJ, Lindgren CM: Type 2 diabetes: new genes, new understanding. Trends Genet 2008;24:613-621.

-2 Ridderstrale M, Groop L: Genetic dissection of type 2 diabetes. Mol Cell Endocrinol 2009; 297:10-17.

-3 Lindgren CM: Mechanisms of disease: genetic insights into the etiology of type 2 diabetes and obesity. Nat Clin Pract 2007;4:156163.

4 Florez JC: The genetics of type 2 diabetes: a realistic appraisal in 2008. J Clin Endocrinol Metab 2008;93:4633-4642.

5 Müller G: Personalized prognosis and diagnosis of type II diabetes - vision or fiction? Pharmacology 2010;85:168-187.

-6 Lusis AJ, Attie AD, Reue K: Metabolic syndrome: from epidemiology to systems biology. Nature Genet 2008;9:819-830.

7 Gibson G: Decanalization and the origin of complex disease. Nature 2009;10:134-140.

-8 Janssens ACJW, van Duijn CM: Genomebased prediction of common diseases: advances and prospects. Hum Mol Genet 2008; 17:R166-R173.

9 McCarthy MI, Smedley D, Hide W: New methods for finding disease-susceptibility genes: impact and potential. Genome Biol 2003;4:119.

10 Rothman KJ, Greenland S: Causation and causal interference in epidemiology. Am J Pub Health 2005;95(suppl 1):S144-S150.

- 11 Edwards KL, Hutter CM, Wan JY, Kim H, Monks SA: Genome-wide linkage scan for the metabolic syndrome: The GENNID study. Obesity 2008;16:1596-1601.

12 Janssens ACJW, Pardo MC, Steyerberg EW, van Dujin CM: Revisiting the clinical validity of multiplex genetic testing in complex diseases. Am J Hum Genet 2004;74:585-588.

13 Li SD, Huang L: Non-viral is superior to viral gene delivery. J Controlled Release 2007;123: 181-183.

14 Xie FY, Woodle MC, Lu PY: Harnessing in vivo siRNA delivery for drug discovery and therapeutic development. Drug Discovery Today 2006;11:67-73.

15 Martin SE, Caplen NJ: Development of new RNAi therapeutics. Histol Histopathol 2007; 22:211-217.

-16 Leung RK, Whittaker PA: RNA interference: from gene silencing to gene-specific therapeutics. Pharmacol Ther 2005;107:222-239.

-17 Kim DH, Rossi JJ: Strategies for silencing human disease using RNA interference. Nat Rev Genet 2007;8:173-184

18 Suda T, Suda K, Liu D: Computer-assisted hydrodynamic gene delivery. Mol Ther 2008; 16:1098-1104.

19 Gao K, Huang L: Nonviral methods for siRNA delivery. Mol Pharmaceut 2009;6: 651-658.

20 Arbit E: The physiological rationale for oral insulin administration. Diabetes Technol Ther 2004;6:510-517.
21 Lasch F, Schönbrunner E: Weitere Untersuchungen über die enterale Insulinresorption, über den Schutz des Insulins gegen Trypsin. Naunyn Schmiedeberg Arch Pharmacol 1936;182:452-458.

22 Young LE, Phillips WA, Murlin JR: New results on the absorption of insulin from the alimentary tract. Am J Physiol 1939;128:8191

23 Pauletti G, Gangwar S, Knipp GT, Nerurkar MM, Okuma FW, Tamura K, Siahaan TJ, Borchardt RT: Structural requirements for intestinal absorption of peptide drugs. J Control Release 1996;41:3-17.

24 Moriya $\mathrm{H}$, Moriwaki C, Akimote S, Yamaguchi K, Iwadareet M: Studies on the passage of alpha-chymotrypsin across the intestine. Chem Pharm Bull 1967;15:1662-1668.

25 Wang W: Oral protein drug delivery. J Drug Target 1996;4:195-232.

26 Woodley JF: Enzymatic barriers for GI peptide and protein delivery. Crit Rev Ther Drug Carrier Syst 1994;11:61-95.

27 Guyton AC: Digestion and absorption in the gastrointestinal tract; gastrointestinal disorders; in Human Physiology and Mechanisms of Disease, ed 5. Philadelphia, WB Saunders, 1992, pp 500-509.

28 Bai JPF, Chang LL: Transepithelial transport of insulin. I. Insulin degradation by insulindegrading enzyme in small intestinal epithelium. Pharm Res 1995;12:1171-1175.

29 Schwendeman SP, Cardamone M, Klibanov A, Langer R: Stability of proteins and their delivery from biodegradable polymer microspheres; in Cohen S, Bernstein H (eds): Microparticulate Systems for the Delivery of Proteins and Vaccines. New York, Marcel Dekker, 1996, pp 1-49.

30 Ziv E, Lior O, Kidron M: Absorption of protein via the intestinal wall. Biochem Pharm 1987;36:1035-1039.

31 Carino PC, Mathiowitz E: Oral insulin delivery. Adv Drug Deliv Rev 1999;35:249-257.

32 Aspden TJ, Mason JD, Jones NS: Chitosan as a nasal delivery system: the effect of chitosan solutions on in vitro and in vivo mucocilliary transport rates in human turbinates and volunteers. J Pharm Sci 1997;86:509-513.

33 Mathiowitz E, Jacob JS, Jong YS, Carino GP, Chickering DE, Chaturvedi P, Santos CA, Vijayaraghavan K, Montgomery S, Bassett M, Morrell C: Biologically erodible microspheres as potential oral drug delivery systems. Nature 1997;386:410-414.

34 Damge C, Michael C, Aprahamian M, Couvreur P: New approach for oral administration of insulin with polyalkylcyanoacrylatenanocapsules as oral carrier. Diabetes 1988:37:247-251.

35 Takka S, Acarturk F: Calcium alginate microparticles for oral administration. I. Effect of sodium alginate type on drug release and drug entrapment efficiency. J Microencapsul 1999;16:275-290.
36 Rowsen ML, Dileep KJ, Sharma CP: $\beta$ cyclodextrin-insulin-encapsulated chitosan/alginate matrix: oral delivery system. J Appl Polym Sci 2000;75:1089-1096.

-37 Dapergolas G, Gregoriadis G: Hypoglycaemic effect of liposome-entrapped insulin administered intragastrically into rats. Lancet 1976;2:824-827.

- 38 Pappo J, Ermak TH: Uptake and translocation of fluorescent latex particles by rabbit Peyer's patch follicle epithelium: a quantitative model for M cell uptake. Clin Exp Immunol 1989;76:144-148.

-39 Yamamoto A, Taniguchi T, Rikyuu K, Tsuji T, Fujita T, Murakami M, Muranishi S: Effects of various protease inhibitors on the intestinal absorption and degradation of insulin in rats. Pharm Res 1994;11:1496-1500.

-40 Abuchowski A, McCoy JR, Palczuk NC, van Es T, Davis FF: Effect of covalent attachment of polyethylene glycol on immunogenicity and circulating life of bovine liver catalase. J Biol Chem 1977;252:3582-3586.

41 Lowman AM, Morishita M, Kajita M, Nagai T, Peppas NA: Oral delivery of insulin using pH-responsive complexation gels. Int J Pharm 1999;88:933-937.

42 Hosny EA, Al-Shora HI, Elmazar MMA: Oral delivery of insulin from enteric-coated capsules containing sodium salicylate: effect on relative hypoglycaemia of diabetic beagle dogs. Int J Pharm 2002;237:71-76.

43 Clement S, Still JG, Kosutic G, McAllister RG: Oral insulin product hexyl-insulin monoconjugate 2 (HIM2) in type 1 diabetes mellitus: the glucose stabilization effects of HIM2. Diabetes Technol Ther 2002;4:459466.

44 Palin KJ, Philipps AJ, Ning A: The oral absorption of cefoxitin from oil and emulsion vesicles in rats. Int J Pharm 1986;33:99-104.

45 Mesiha M, Plakogiannis F, Vejosoth S: Enhanced oral absorption of insulin from desolvated fatty acid-sodium glycocholate emulsions. Int J Pharm 1994;111:213-216.

46 Wang YZ, Yu L, Han L, Sha XY, Fang XL: Difunctional pluronic copolymer micelles for paclitaxel delivery: synergistic effect of folate-mediated targeting and Pluronic-mediated overcoming multidrug resistance in tumor cell lines. Int J Pharm 2007;337:63-73.

47 Matsumara Y: Polymeric micellar delivery systems in oncology. Jpn J Clin Oncology 2008;38:793-802.

48 Fasano A, Uzzau S: Modulation of intestinal tight junctions zona occludens toxin permits enteral administration of insulin and other macromolecules in an animal model. J Clin Invest 1997;99:1158-1164.

- 49 Uhrich KE, Cannizzaro SM, Langer RS, Shakesheff KM: Polymeric systems for controlled drug release. Chem Rev 1999;99: 3181-3198. 
-50 Soussan E, Cassel S, Blanzat M, Rico-Lattes I: Drug delivery by soft matter: matrix and vesicular carriers. Angew Chem Int Ed 2009; 48:274-288.

51 Ebbesen M, Jensen TG: Nanomedicine: techniques, potentials, and ethical implications. J Biomed Biotechnol 2006, DOI 10.1155/ JBB/2006/51516.

-52 Gullotti E, Yeo Y: Extracellularly activated nanocarriers: a new paradigm of tumor targeted drug delivery. Mol Pharmaceut 2009;6: 1041-1051.

-53 Yang T, Choi MK, Cui FD, Kim JS, Chung SJ, Shim CK, Kim DD: Preparation and evaluation of paclitaxel-loaded PEGylated immunoliposome. J Controlled Release 2007;120: 169-177.

54 Kirpotin DB, Drummond DC; Shao Y, Shalaby MR, Hong KL, Nielsen UB, Marks JD, Benz CC, Park JW: Antibody targeting of long-circulating lipidic nanoparticles does not increase tumor localization but does increase internalization in animal models. Cancer Res 2006;66:6732-6740.

55 Mamot C, Drummond DC, Noble CO, Kallab V, Guo ZX, Hong KL, Kirpotin DB, Park JW: Epidermal growth factor receptor-targeted immunoliposomes significantly enhance the efficacy of multiple anticancer drugs in vivo. Cancer Res 2005;65:1163111638.

56 Dagar S, Krishnadas A, Rubinstein I, Blend MJ, Onyuksel H: VIP grafted sterically stabilized liposomes for targeted imaging of breast cancer: in vivo studies. J Controlled Release 2003;91:123-133.

57 Yokoyama M: Drug targeting with nanosized carrier systems. J Artif Organs 2005;8: 77-84.

58 Gerweck LE, Seetharaman K: Cellular pH gradient in tumor versus normal tissue: Potential exploitation for the treatment of cancer. Cancer Res 1996;56:1194-1198.

59 Egeblad M, Werb Z: New functions for the matrix metalloproteinases in cancer progression. Nat Rev Cancer 2002;2:161-174.

-60 Montcourrier P, Silver I, Farnoud R, Bird I, Rochefort H: Breast cancer cells have a high capacity to acidify extracellular milieu by a dual mechanism. Clin Exp Metastasis 1997; 15:382-392.

-61 Swallow CJ, Grinstein S, Rotstein OD: A vascuolar type $\mathrm{H}(+)$-ATPase regulates cytoplasmic $\mathrm{pH}$ in murine macrophages. J Biol Chem 1990;265:7645-7654

-62 Mok H, Bae KH, Ahn C-H, Park TG: PEGylated and MMP-2 specifically dePEGylated quantum dots: comparative evaluation of cellular uptake. Langmuir 2009;25:1645-1650.

-63 Scherer RL, VanSaun MN, McIntyre JO, Matrisian LM: Optical imaging of matrix metalloproteinase-7 activity in vivo using a proteolytic nanobeacon. Mol Imaging 2008;7: 118-131.
64 Weissleder R, Tung CH, Mahmood U, Bogdanov A: In vivo imaging of tumors with protease-activated near-infrared fluorescent probes. Nat Biotechnol 1999;17:375-378.

65 Nosjean O, Briolay A, Roux B: Mammalian GPI proteins: sorting, membrane residence and functions. Biochim Biophys Acta 1997; 1331:153-186.

66 Brewis IA, Ferguson MAJ, Mehlert A, Turner AJ, Hooper NM: Structures of the glycosylphosphatidylinositol anchors of porcine and human erythrocyte renal membrane dipeptidase. Comprehensive structural studies on the porcine anchor and interspecies comparison of the glycan core structures. J Biol Chem 1995;270:22946-22956.

-67 Ikezawa H: Glyosylphosphatidylinositol (GPI)-anchored proteins. Biol Pharm Bull 2002;25:409-417.

68 Englund PT: The structure and biosynthesis of glycosyl phosphatidylinositol protein anchors. Annu Rev Biochem 1993;62:121-139.

69 Tiede A, Bastisch I, Schubert J, Orlean P, Schmidt RE: Biosynthesis of glycosylphosphatidylinositols in mammals and unicellular microbes. Biol Chem 1999;380:503-523.

70 Orlean P, Menon AK: Thematic review series: lipid posttranslational modifications. GPI anchoring of protein in yeast and mammalian cells, or: how we learned to stop worrying and love glycophospholipids. J Lipid Res 2007;48:993-1011.

71 Singer SJ, Nicolson GL: The fluid mosaic model of the structure of cell membranes. Science 1972;175:720-728.

72 Jacobson K, Sheets ED, Simson R: Revisiting the fluid mosaic model of membranes. Science 1995;268:1441-1446.

73 Brown D, London L: Functions of lipid rafts in biological membranes. Annu Rev Cell Dev Biol 1998;14:111-136.

74 Brown D: Interactions between GPI-anchored proteins and membrane lipids. Trends Cell Biol 1992;2:338-343.

75 Varma R, Mayor S: GPI-anchored proteins are organized in submicron domains at the cell surface. Nature 1998;394:798-801.

76 Simons K, Ikonen E: Functional rafts in cell membranes. Nature 1997;387:569-572.

77 Brown DA, Rose JK: Sorting of GPI-anchored proteins to glycolipid-enriched membrane subdomains during transport to the apical cell surface. Cell 1992;68:533-544.

78 Munro S: Lipid rafts: elusive or illusive? Cell 2003;115:377-388.

79 Simons K, Toomre D: Lipid rafts and signal transduction. Nat Rev Mol Cell Biol 2000;1: 31-39.

80 Rajendran L, Simons K: Lipid rafts and membrane dynamics. J Cell Sci 2005;118: 1099-1102.

81 Küng M, Bütikofer P, Brodbeck U, Stadelmann B: Expression of intracellular and GPI-anchored forms of GPI-specific phospholipase D in COS-1 cells. Biochem Biophys Acta 1997;1357:329-338.
82 Bütikofer P, Kuypers FA, Xu CM, Chiu DTY, Lubin B: Enrichment of two glycosyl-phosphatidylinositol-anchored proteins, acetylcholinesterase and decay accelerating factor, in vesicles released from human red blood cells. Blood 1989;74:1481-1489.

83 Hoener MC, Stieger S, Brodbeck U: Isolation and characterization of a phosphatidylinositol-glycan-anchor-specific phospholipase D from bovine brain. Eur J Biochem 1990;190: 593-600.

84 Low MG, Huang KS: Factors affecting the ability of glycosylphosphatidylinositol-specific phospholipase D to degrade the membrane anchors of cell surface proteins. Biochem J 1991;279:483-488.

>85 Müller G, Dearey E-A, Korndörfer A, Bandlow W: Stimulation of a glycosyl-phosphatidylinositol-specific phospholipase by insulin and the sulfonylurea, glimepiride, in rat adipocytes depends on increased glucose transport. J Cell Biol 1994;126:1267-1276.

86 Müller G, Schulz A, Wied S, Frick W: Regu lation of lipid raft proteins by glimepirideand insulin-induced glycosylphosphatidylinositol-specific phospholipase $\mathrm{C}$ in rat adipocytes. Biochem Pharmacol 2005;69: 761-780.

87 Müller G: The mode of action of glimepiri-de - beyond insulin secretion. Curr Med Chem 2005;5:499-518.

88 Müller G, Wetekam E-M, Jung C, Bandlow W: Membrane association of lipoprotein lipase and a cAMP-binding ectoprotein in rat adipocytes. Biochemistry 1994;33:1214912159.

89 Eisenhaber B, Maurer-Stroh S, Novatchkova $\mathrm{M}$, Schneider G, Eisenhaber F: Enzymes and auxiliary factors for GPI lipid anchor biosynthesis and post-translational transfer to proteins. Bioessays 2003;25:367-385.

90 Shams-Eldin H, Azzouz N, Niehus S, Smith TK, Schwarz RT: An efficient method to express GPI-anchor proteins in insect cells. Biochem Biophys Res Commun 2008;365: 657-663.

$>91$ Walter EI, Ratnoff WD, Long KE, Kazura JW, Medof ME: Effect of glycoinositolphospholipid anchor lipid groups on functional properties of decay-accelerating factor protein in cells. J Biol Chem 1992;267:12451252.

92 Eberl H, Tittmann P, Glockshuber R: Characterization of recombinant, membrane-attached full-length prion protein. J Biol Chem 2004;279:25058-25065.

$>93$ Müller G, Bandlow W: Lipolytic membrane release of two phosphatidylinositol-anchored cAMP receptor proteins in yeast alters their ligand-binding parameters. Arch Biochem Biophys 1994;308:504-514. 
94 Barboni E, Rivero BP, George AJ, Martin SR; Renoup DV, Hounsell EF, Barber PC, Morris RJ: The glycophosphatidylinositol anchor affects the conformation of Thy-1 protein. J Cell Sci 1995;108:487-497.

$\checkmark 95$ Paulik MG, Wise AR, Forstner MB, Groves JT, Bertozzi CR: Synthetic analogues of glycosylphosphatidylinositol-anchored proteins and their behaviour in supported lipid bilayers. J Am Chem Soc 2007;129:1154311550.

96 Lehto MT, Sharom FJ: Proximity of the protein moiety of a GPI-anchored protein to the membrane surface: a FRET study. Biochemistry 2002;41:8368-8376.

\$7 Yu J, Fischman DA, Steck TL: Selective solubilization of proteins and phospholipids from red blood cell membranes by nonionic detergents. J Supramol Struct 1973;1: 233-243.

98 Müller G, Korndörfer A, Saar K, KarbeThönges B, Fasold H, Müllner S: 4'-Amino-benzamido-taurocholic acid selectively solubilizes glycosyl-phosphatidylinositolanchored membrane proteins and improves lipolytic cleavage of their membrane anchors by specific phospholipases. Arch Biochem Biophys 1994;309:329-340.

-99 Premkumar DR, Fukuoka Y, Sevlever D, Brunschwig E, Rosenberry TL, Tykocinski ML: Properties of exogenously added GPIanchored proteins following their incorporation into cells. J Cell Biochem 2001;82: 234-245.

100 Kooyman DL, Byrne GW, Logan JS: Glycosyl phosphatidylinositol anchor. Exp Nephrol 1998;6:148-151.

- 101 Medof ME, Nagarajan S, Tykocinski ML: Cell-surface engineering with GPI-anchored proteins. FASEB J 1996;10:574-586.

102 Civenni G, Test ST, Brodbeck U, Bütikofer P: In vitro incorporation of GPI-anchored proteins into human erythrocytes and their fate in the membrane. Blood 1998;9:1178411792 .

- 103 McHugh RS, Ahmed SN, Wang YC, Sell KW, Selvavaj P: Construction, purification, and functional incorporation on tumor cells of glycolipid-anchored human B7-1 (CD80). Proc Natl Acad Sci USA 1995;92: 8059-8063.

- 104 McHugh RS, Nagarajan S, Wang YC, Sell KW, Selvaraj P: Protein transfer of glycosylphosphatidylinositol-B7-1 into tumor cell membranes: a novel approach to tumor immunotherapy. Cancer Res 1999;59:24332437.

>105 Suzuki K, Okumura Y: GPI-linked proteins do not transfer spontaneously from erythrocytes to liposomes. New aspects of reorganization of the cell membrane. Biochemistry 2000;39:9477-9485.

-106 Ilangumaran S, Robinson PJ, Hoessli DC: Transfer of exogenous glycosylinositol (GPI)-linked molecules to plasma membranes. Trends Cell Biol 1996;6:163-169.
107 Zhang F, Schmidt WG, Hou Y, Williams AF, Jacobson K: Spontaneous incorporation of the glycosyl-phosphatidylinositollinked protein Thy-1 into cell membranes. Proc Natl Acad Sci USA 1992;89:52315235.

108 Medof ME, Kinoshita T, Nussenzweig V: Inhibition of complement activation on the surface of cells after incorporation of decay-accelerating factor (DAF) into their membranes. J Exp Med 1984;160:15581578.

109 Olschewski D, Seidel R, Miesbauer M, Rambold AS, Oesterhelt D, Winklhofer KF, Tatzelt J, Engelhard M, Becker CF: Semisynthetic murine prion protein equipped with a GPI anchor mimic incorporates into cellular membranes. Chem Biol 2007;14: 994-1006.

110 Kooyman DL, Byrne GW, Logan JS: Glycosyl phosphatidylinositol anchor. Exp Nephrol 1998;6:148-151.

111 Müller G, Frick W: Signalling via caveolin: involvement in the cross-talk between phosphoinositolglycans and insulin. Cell Mol Life Sci 1999;56:945-970.

112 Müller G, Jung C, Wied S, Welte S, Jordan $\mathrm{H}$, Frick W: Redistribution of glycolipid raft domain components induces insulin-mimetic signaling in rat adipocytes. Mol Cell Biol 2001;21:4553-4567.

113 Lisanti MP, Scherer PE, Tang ZL, Sargiacomo M: Caveolae, caveolin and caveolinrich membrane domains: a signalling hypothesis. Trends Cell Biol 1994;4:231-238.

-114 Mayor S, Rothberg KG, Maxfield FR: Sequestration of GPI-anchor proteins in caveolae triggered by cross-linking. Science 1994;264:1948-1951.

115 Parton RG, Joggerst B, Simons K: Regulated internalization of caveolae. J Cell Biol 1994; 127:1199-1215.

116 Zurzolo C, Lisanti MP, Caras IW, Nitsch L, Rodriguez-Boulan E: Glycosylphosphatidylinositol-anchored proteins are preferentially targeted to the basolateral surface in Fischer rat thyroid epithelial cells. J Cell Biol 1993;121:1031-1039.

117 Fivaz M, Vilbois F, Thurnheer S, Pasquali C, Abrami L, Bickel PE, Parton RG, van der Goot FG: Differential sorting and fate of endocytosed GPI-anchored proteins. EMBO J 2002;21:3989-4000.

118 Lakhan SE, Sabharanjak S, De A: Endocytosis of glycosylphosphatidylinositol-anchored proteins. J Biomed Sci 2009;16:93 DOI: $10.1186 / 1423-0127-16-93$.

119 Deckert M, Ticchioni M, Bernard A: Endocytosis of GPI-anchored proteins in human lymphocytes: role of glycolipid-based domains, actin cytoskeleton, and protein kinases. J Cell Biol 1996;133:791-799.

120 Sabharanjak S, Sharma P, Parton RG, Mayor S: GPI-anchored proteins are delivered to recycling endosomes via a distinct cdc42regulated, clathrin-independent pinocytic pathway. Dev Cell 2002;2:411-423.
121 Naslavsky N, Weigert R, Donaldson JG: Characterization of a nonclathrin endocytoc pathway: membrane cargo and lipid requirements. Mol Biol Cell 2004;15:35423552.

122 Zhang F, Crise B, Su B, Hou Y, Rose JK, Bothwell A, Jacobson K: Lateral diffusion of membrane-spanning and glycosylphosphatidylinositol-linked proteins: toward establishing rules governing the lateral mobility of membrane proteins. J Cell Biol 1991;115:75-86.

123 Keller GA, Siegel MW, Caras IW: Endocytosis of glycophospholipid-anchored and transmembrane forms of CD4 by different endocytic pathways. EMBO J 1992;11:863874.

124 Bamezai A, Goldmacher VS, Rock KL: Internalization of glycosylphosphatidylinositol (GPI)-anchored lymphocyte proteins. II. GPI-anchored and transmembrane molecules internalize through distinct pathways. Eur J Immunol 1992;22:15-21.

125 Müller G, Jung C, Wied S: Translocation of glycosylphosphatidylinositol-anchored proteins from plasma membrane microdomains to lipid droplets in rat adipocytes is induced by palmitate, $\mathrm{H}_{2} \mathrm{O}_{2}$ and the sulfonylurea drug, glimepiride. Mol Pharmacol 2008;73:1513-1529.

$>126$ Müller G, Wied S, Jung C, Over S: Translocation of glycosylphosphatidylinositol-anchored proteins to lipid droplets and inhibition of lipolysis in rat adipocytes is mediated by reactive oxygen species. Br J Pharmacol 2008;154:901-913.

127 Müller G, Wied S, Walz N, Jung C: Translocation of glycosylphosphatidylinositol-anchored proteins from plasma membrane microdomains to lipid droplets in rat adipocytes is induced by palmitate, $\mathrm{H}_{2} \mathrm{O}_{2}$ and the sulfonylurea drug, glimepiride. $\mathrm{Mol}$ Pharmacol 2008;73:1513-1529.

128 Müller G, Over S, Wied S, Frick W: Association of (c)AMP-degrading glycosylphosphatidylinositol-anchored proteins with lipid droplets is induced by palmitate, $\mathrm{H}_{2} \mathrm{O}_{2}$ and the sulfonylurea drug, glimepiride, in rat adipocytes. Biochemistry 2008;47: 1274-1287.

129 Müller G, Wied S, Over S, Frick W: Inhibition of lipolysis by palmitate, $\mathrm{H}_{2} \mathrm{O}_{2}$ and the sulfonylurea drug, glimepiride, in rat adipocytes depends on cAMP degradation by lipid droplets. Biochemistry 2008;47:12591273.

130 Ducharme NA, Bickel PE: Lipid droplets in lipogenesis and lipolysis. Endocrinoloy 2008;149:942-949.

>131 Fujimoto T, Ohsaki Y, Cheng J, Suzuki M, Shinohara Y: Lipid droplets: a classic organelle with new outfits. Histochem Cell Biol 2008;130:263-279. 
132 Ohsaki Y, Cheng J, Suzuki M, Shinohara Y, Fujita A, Fujimoto T: Biogenesis of cytoplasmic lipid droplets: from the lipid ester globule in the membrane to the visible structure. Biochim Biophys Acta 2009; 1791:399-407.

133 Cermelli S, Guo Y, Gross S, Welte M: The lipid-droplet proteome reveals that droplets are a protein-storage depot. Curr Biol 2006; 16:1783-1795.

-134 Boulant S, Targett-Adams P, McLauchlan J: Disrupting the association of hepatitis $\mathrm{C}$ virus core protein with lipid droplets correlates with a loss in production of infectious virus. J Gen Virol 2007;88:2204-2213.

-135 Miyanari Y, Atsuzawa K, Usada N, Watashi K, Hishiki T, Zayas M, Bartenschlager R, Wakita T, Hijikata T, Shimotohno K: The lipid droplet is an important organelle for hepatitis $\mathrm{C}$ virus production. Nat Cell Biol 2007;9:1089-1097.

-136 Cho SY, Shin ES, Park PJ, Shin DW, Chang HK, Kim D, Lee HH, Lee JH, Kim SH, Song MJ, Chang IS, Lee OS, Lee TR: Identification of mouse Prp19p as a lipid droplet protein. J Biol Chem 2007;282:24562465.

-137 Cocchiaro J, Kumar Y, Fischer E, Hackstadt T, Valdivia R: Cytoplasmic lipid droplets are translocated into the lumen of the Chlamydia trachomatis parasitophorous vacuole. Proc Natl Acad Sci USA 2008;105: 9379-9384.

-138 Ploegh HL: A lipid-based model for the creation of an escape hatch from the endoplasmic reticulum. Nature 2007;448:435438.

139 Aoki N, Jin-no S, Nakagawa Y, Asai N, Arakawa E, Tamura N: Identification and characterization of microvesicles secreted by 3T3-L1 adipocytes: redox- and hormonedependent induction of milk fat globuleepidermal growth factor 8-associated microvesicles. Endocrinology 2007; 148: 3850-3862.

-140 Müller G, Jung C, Straub J, Wied S, Kramer $\mathrm{W}$ : Induced release of membrane vesicles from rat adipocytes containing glycosylphosphatidylinositol-anchored microdomain and lipid droplet signalling proteins. Cell Signal 2009;21:324-338.

-141 Müller G, Jung C, Wied S, Biemer-Daub G: Induced translocation of glycosylphosphatidylinositol-anchored proteins from lipid droplets to adiposomes in rat adipocytes. Br J Pharmacol 2009;158:749-770.

- 142 de Gassart A, Geminard C, Fevrier B, Raposo G, Vidal M: Lipid raft-associated protein sorting in exosomes. Blood 2003;102: 4336-4344.

- 143 Del Conde I, Shrimpton CN, Thiagarajan P, Lopez JA: Tissue-factor-bearing microvesicles arise from lipid rafts and fuse with activated platelets to initiate coagulation. Blood 2005;106:1604-1611.
144 Anderson SM, Yu G, Giattina M, Miller JL: Intercellular transfer of a glycosylphosphatidylinositol (GPI)-linked protein: release and uptake of CD4-GPI from recombinant adeno-associated virus-transduced HeLa cells. Proc Natl Acad Sci USA 1996;93: 5894-5898.

145 Cauwenberghs S, Feijge MA, Harper AG, Sage SO, Curvers J, Heemskerk JW: Shedding of procoagulant microparticles from unstimulated platelets by integrin-mediated destabilization of actin cytoskeleton. FEBS Lett 2006;580:5313-5320.

-146 Scott RE, Perkins RG, Zschunke MA, Hoerl BJ, Maercklein PB: Plasma membrane vesiculation in 3T3 and SV3T3 cells. J Cell Sci 1979;35:229-238.

147 Black PN: Shedding from normal and cancer-cell surfaces. N Engl J Med 1980;303: 1415-1420.

148 Heijnen HF, Schiel AE, Fijnheer R, Geuze HJ, Sixma JJ: Activated platelets release two types of membrane vesicles: microvesicles by surface shedding and exosomes derived from exocytosis of multivesicular bodies and alpha-granules. Blood 1999;94:37913799.

149 Piccin A, Murphy WG, Smith OP: Circulating microparticles: pathophysiology and clinical implications. Blood Rev 2007;21: 157-171.

150 Denzer K, Kleijmeer MJ, Heijnen HF, Stoorvogel W, Geuze HJ: Exosome: from internal vesicle of the multivesicular body to intercellular signaling device. J Cell Sci 2000;113:3365-3374

151 Fevrier B, Raposo G: Exosomes: endosomal-derived vesicles shipping extracellular messages. Curr Opin Cell Biol 2004;16: 415-421.

152 Keller S, Sanderson MP, Stoeck A, Altevogt P: Exosomes: from biogenesis and secretion to biological function. Immunol Lett 2006; 107:102-108.

153 Pap E, Pallinger E, Pasztoi M, Falus A: Highlights of a new type of intercellular communication: microvesicle-based information transfer. Inflamm Res 2009;58:1-8.

154 Stoorvogel W, Kleijmeer MJ, Geuze H, Raposo G: The biogenesis and functions of exosomes. Traffic 2002;3:321-330.

155 Thery C, Zitvogel L, Amigorena S: Exosomes: composition, biogenesis and function. Nat Rev Immunol 2002;3:569-579.

156 Cocucci E, Racchetti G, Meldolesi J: Shedding microvesicles: artefacts no more. Trends Cell Biol 2009;19:43-51.

157 Poste G, Nicolson GL: Arrest and metastasis of blood-born tumor cells are modified by fusion of plasma membrane vesicles from highly metastatic cells. Proc Natl Acad Sci USA 1980;77:399-403.

158 Al-Nedawi K, Meehan B, Micallef J, Lhotak V, May L, Guha A, Rak J: Intercellular transfer of the oncogenic receptor EGFRvIII by microvesicles derived from tumour cells. Nature Cell Biol 2008;10:619-624.
159 Bastida E, Ordinas A, Escolar G, Jamieson GA: Tissue factor in microvesicles shed from U87MG human glioblastoma cells induces coagulation, platelet aggregation, and thrombogenesis. Blood 1984;64:177184.

160 Freyssinet J-M: Cellular microparticles: what are they bad or good for? J Thromb Haemost 2003;1:1655-1662.

161 Gould SJ, Booth AM, Hildreth JE: The Trojan exosome hypothesis. Proc Natl Acad Sci USA 2003;100:10592-10597.

162 Johnstone RM: Exosomes biological significance: a concise review. Blood Cells Mol Dis 2006;36:315-321.

163 Dunn DE, Yu J, Nagarajan S, Devetten M, Weichold FF, Medof ME, Young NS, Liu JM: A knock-out model of paroxysmal nocturnal hemoglobinuria: Pig-a(-) hematopoiesis is reconstituted following intercellular transfer of GPI-anchored proteins. Proc Natl Acad Sci USA 1996;93:79387943.

164 Medof ME, Kinoshita T, Silber R, Nussenzweig V: Amelioration of lytic abnormalities of paroxysmal nocturnal hemoglobinuria with decay accelerating factor. Proc Natl Acad Sci USA 1985;82:2980-2984.

165 Kooyman DL, Byrne GW, McClellan S, Nielsen D, Tone M, Waldmann H, Coffman TM, McCurry KR, Platt JL, Logan JS: In vivo transfer of GPI-linked complement restriction factors from erythrocytes to the endothelium. Science 1995;269:89-92.

166 Sloand EM, Mainwaring L, Keyvanfar K, Chen J, Maciejewski J, Klein HG, Young NS: Transfer of glycosylphosphatidyl-anchored proteins to deficient cells after erythrocyte transfusion in paroxysmal nocturnal hemoglobinuria. Blood 2004; 104:3782-3788.

167 Liu T, Li R, Pan T, Liu D, Petersen RB, Wong BS, Gambetti P, Sy MS: Intercellular transfer of the cellular prion protein. J Biol Chem 2002;277:47671-47678.

168 Wolf P: The nature and significance of platelet products in human plasma. Br J Haematol 1967;13:269-288.

169 Sloand EM, Maciejewski JP, Dunn D, Moss J, Brewer B, Kirby M, Young NS: Correction of the PNH defect by GPI-anchored protein transfer. Blood 1998;92:4439-4445.

170 Müller G, Wied S, Jung C, Straub J: Coordinated regulation of esterification and lipolysis by palmitate, $\mathrm{H}_{2} \mathrm{O}_{2}$ and the anti-diabetic sulfonylurea drug, glimepiride, in rat adipocytes. Eur J Pharmacol 2008;597:618.

171 Müller G, Wied S, Jung C, Biemer-Daub G, Frick W: Transfer of glycosylphosphatidylinositol-anchored 5'-nucleotidase CD73 from adiposomes into rat adipocytes stimulates lipid synthesis. Br J Pharmacol 2010; 160:878-891. 
-172 Müller G, Wied S, Jung C, Frick W, BiemerDaub G: Inhibition of lipolysis by adiposomes containing glycosylphosphatidylinositol-anchored Gcel protein in rat adipocytes. Arch Physiol Biochem 2010; 116:28-41.

173 Tso P, Balint J, Bishop M, Rodgers J: Acute inhibition of intestinal lipid transport by Pluronic L-81 in the rat. Am J Physiol Gastrointest Liver Physiol 1981,241:G487G497.

- 174 Phan CT, Tso P: Intestinal lipid absorption and transport. Front Biosci 2001;6:d299d319.

-175 Mansbach II CM, Gorelick FS: Development of physiological regulation of intestinal lipid absorption. II. Dietary lipid absorption, complex lipid synthesis, and the intracellular packaging and secretion of chylomicrons. Am J Physiol Gastrointestinal Liver Physiol 2007;293:G645-G650.

176 Wang Y, Iordanov H, Swietlicki EA, Wang L, Fritsch C, Coleman T, Semenkovich CF, Levin MS, Rubin DC: Targeted intestinal overexpression of the immediate early gene tis7 in transgenic mice increases triglyceride absorption and adiposity. J Biol Chem 2005;280:34764-34775

- 177 Drover VA, Ajmal M, Nassir F, Davidson NO, Nauli AM, Sahoo D, Tso P, Abumrad NA: CD36 deficiency impairs intestinal lipid secretion and clearance of chylomicrons from the blood. J Clin Invest 2005;115: 1290-1297.

178 Nakano T, Inoue I, Koyama I, Kanazawa K, Nakamura K-i, Narisawa S, Tanaka K, Akita M, Masuyama T, Seo M, Hokari S, Katayama S, Alpers DH, Millan JL, Komoda T: Disruption of the murine intestinal alkaline phosphatase gene Akp3 impairs lipid transcytosis and induces visceral fat accumulation and hepatic steatosis. Am J Physiol Gastrointest Liver Physiol 2007;292: G1439-G1449.

-179 Fielding BA, Callow J, Owen RM, Samra JS, Matthews DR, Frayn KN: Postprandial lipemia: the origin of an early peak studied by specific dietary fatty acid intake during sequential meals. Am J Clin Nutr 1996;63: 36-41.
180 Jackson KG, Robertson MD, Fielding BA, Frayn KN, Williams CM: Olive oil increases the number of triacylglycerol-rich chylomicron particles compared with other oils: an effect retained when a second standard meal is fed. Am J Clin Nutr 2002;76:942949.

181 Mansbach II CM, Nevin P: Intracellular movement of triacylglycerols in the intestine. J Lipid Res 1998;39:963-968.

182 Tso P, Balint JA, Rodgers JB: Effect of hydrophobic surfactant (Pluronic L-81) on lymphatic lipid transport in the rat. Am J Physiol Gastrointest Liver Physiol 1980; 239:G348-G353.

183 Mansbach II CM, Dowell R: Effect of increasing lipid loads on the ability of the endoplasmic reticulum to transport lipid to the Golgi. J Lipid Res 2000;41:605-612.

184 Cartwright IJ, Plonne D, Higgins JA: Intracellular events in the assembly of chylomicrons in rabbit enterocytes. J Lipid Res 2000;41:1728-1739.

185 Robertson M, Parkes M, Warren B, Ferguson D, Jackson K, Jewell D, Frayn K: Mobilisation of enterocyte fat stores by oral glucose in humans. Gut 2003;52:834-839.

186 Murphy DJ: The biogenesis and functions of lipid bodies in animals, plants and microorganisms. Prog Lipid Res 2001;40:325438.

187 Zhu J, Lee B, Buhman KK, Cheng JX: A dynamic, cytoplasmic triacylglycerol pool in enterocytes revealed by ex vivo and in vivo coherent anti-Stokes Raman scattering imaging. J Lipid Res 2009;50:1080-1089.

188 Listenberger LL, Han X, Lewis SE, Cases S, Farese RVJ, Ory DS, Schaffer JE: Triglyceride accumulation protects against fatty acid-induced lipotoxicity. Proc Natl Acad Sci USA 2003;100:3077-3082.

189 Gibbons GF, Islam K, Pease RJ: Mobilisation of triacylglycerol stores. Biochim Biophys Acta 2000;1483:37-57.
190 Danielsen EM, Hansen GH: Lipid raft organization and function in the small intestinal brush border. J Physiol Biochem 2008; 64:377-382.

191 Danielsen EM, Hansen GH: Lipid raft organization and function in brush borders of epithelial cells. Mol Membr Biol 2006;23: 71-79.

192 Lee B, Zhu J, Wolins NE, Cheng JX, Buhman KK: Differential association of adipophilin and TIP47 proteins with cytoplasmic lipid droplets in mouse enterocytes during dietary fat absorption. Biochim Biophys Acta 2009;1791:1173-1180.

193 Bütikofer P, Brodbeck U: Partial purification and characterization of a (glycosyl) inositol phospholipid-specific phospholipase C from peanut. J Biol Chem 1993;268: 17794-17799.

194 Küng M, Bütikofer P, Brodbeck U, Stadelmann B: Expression of intracellular and GPI-anchored forms of GPI-specific phospholipase D in COS-1 cells. Biochim Biophys Acta 1997;1357:329-338.

195 Müller G, Hanekop N, Wied S, Frick W: Cholesterol depletion blocks redistribution of lipid raft components and insulin-mimetic signaling by glimepiride and phosphoinositolglycans in rat adipocytes. Mol Med 2002;8:120-136.

196 Müller G, Petry S: Triacylglycerol, storage and mobilization of human; in Meyers A (ed): Encyclopedia in Biochemistry and Molecular Biology. Weinheim, Wiley VCH, 2005, vol 14, pp 621-704.

197 Iyer H, Khedkar A, Verma M: Oral insulin - a review of current status. Diabetes Obesity Metabol 2010;12:179-185.

198 Kapitza C, Zijlstra E, Heinemann L, Castelli MC, Riley G, Heise T: Oral insulin: a comparison with subcutaneous regular human insulin in patients with type 2 diabetes. Diabetes Care 2010;33:1288-1290.

199 Heinemann L, Jacques Y: Oral insulins and buccal insulins: a critical repraisal. J Diabetes Sci Technol 2009;3:568-584.

200 Billingsley ML: Druggable targets and targeted drugs: enhancing the development of new therapeutics. Pharmacology 2008;82: $239-244$. 